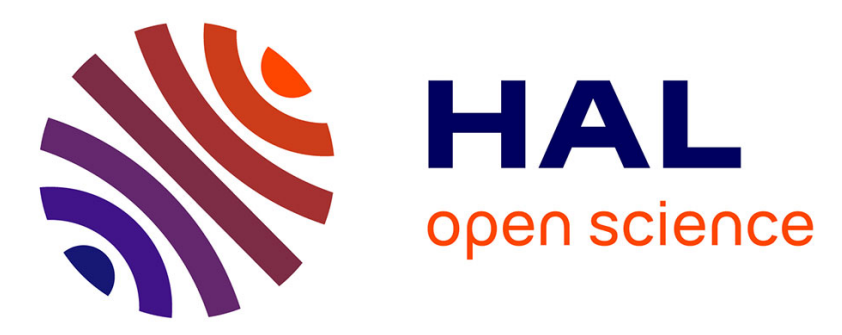

\title{
Molecular and epigenetic regulations and functions of the LAFL transcriptional regulators that control seed development
}

L. Lepiniec, M. Devic, T. Roscoe, D. Bouyer, D.-X Zhou, C. Boulard, S. Baud, B. Dubreucq

\section{To cite this version:}

L. Lepiniec, M. Devic, T. Roscoe, D. Bouyer, D.-X Zhou, et al.. Molecular and epigenetic regulations and functions of the LAFL transcriptional regulators that control seed development. Sexual Plant Reproduction, 2018, 31 (3), pp.291-307. 10.1007/s00497-018-0337-2 . hal-01969458

\section{HAL Id: hal-01969458 \\ https://hal.sorbonne-universite.fr/hal-01969458}

Submitted on 4 Jan 2019

HAL is a multi-disciplinary open access archive for the deposit and dissemination of scientific research documents, whether they are published or not. The documents may come from teaching and research institutions in France or abroad, or from public or private research centers.
L'archive ouverte pluridisciplinaire HAL, est destinée au dépôt et à la diffusion de documents scientifiques de niveau recherche, publiés ou non, émanant des établissements d'enseignement et de recherche français ou étrangers, des laboratoires publics ou privés.

$$
\text { Copyright }
$$


Molecular and epigenetic regulations and functions of the LAFL transcriptional regulators that control seed development.

Lepiniec L. ${ }^{1 *}$, Devic M. ${ }^{2,5}$, Roscoe T.J. ${ }^{2,5}$, Bouyer D. ${ }^{3}$, Zhou D-X. ${ }^{4}$, Boulard C. ${ }^{1}$, Baud S. ${ }^{1}$ and Dubreucq B. $^{1}$

${ }^{1}$ IJPB (Institut Jean-Pierre Bourgin), INRA, AgroParisTech, CNRS, Université Paris-Saclay, RD10, 78026 Versailles, France

2 Régulations Epigénétiques et Développement de la Graine, ERL 5300 CNRS-IRD UMR DIADE, IRD centre de Montpellier, 911 avenue Agropolis BP64501, 34394 Montpellier, FRANCE

${ }^{3}$ Institut de Biologie de I'ENS, CNRS UMR8197, Ecole Normale Supérieure, 46 rue d'Ulm, 75230 Paris cedex 05, France

${ }^{4}$ Institute of Plant Sciences Paris-Saclay (IPS2), Université Paris Sud 11, Université Paris-Saclay, 91405 Orsay, France

${ }^{5}$ Present address: Sorbonne Universités, Université Pierre et Marie Curie (Paris 06) \& Centre National pour la Recherche Scientifique CNRS UMR 7621, Laboratoire d'Océanographie Microbienne, Observatoire Océanologique, F-66650, Banyuls-sur-mer, FRANCE

* Lepiniec L to whom correspondence should be addressed, Loic.Lepiniec@inra.fr

\begin{abstract}
The LAFL (i.e. LEC1, ABI3, FUS3, and LEC2) master transcriptional regulators interact to form different complexes that induce embryo development and maturation, and inhibit seed germination and vegetative growth in Arabidopsis. Orthologous genes involved in similar regulatory processes have been described in various angiosperms including important crop species. Consistent with a prominent role of the LAFL regulators in triggering and maintaining embryonic cell fate, their expression appears finely tuned in different tissues during seed development and tightly repressed in vegetative tissues by a surprising high number of genetic and epigenetic factors. Partial functional redundancies and intricate feedback regulations of the LAFL have hampered the elucidation of the underpinning molecular mechanisms. Nevertheless, genetic, genomic, cellular, molecular, and biochemical analyses implemented during last years have greatly improved our knowledge of the LALF network. Here we summarise and discuss recent progress, together with current issues required to gain a comprehensive insight into the network, including the emerging function of LEC1 and possibly LEC2 as pioneer transcription factors.
\end{abstract}

\title{
Keywords
}

Genetics and epigenetics regulations, pioneer factors, transcriptional network, LAFL regulators, seed development and maturation. 


\section{Content:}

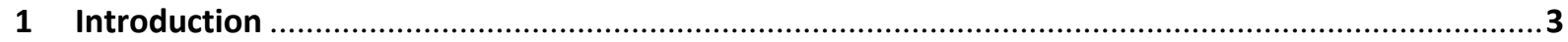

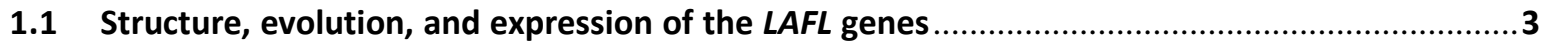

1.2 Redundant and partially overlapping functions in controlling seed development..................4

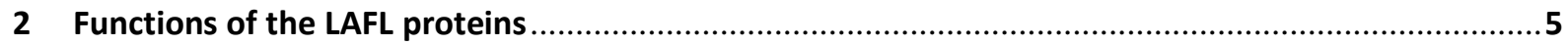

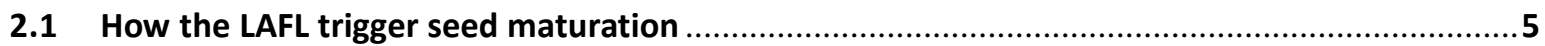

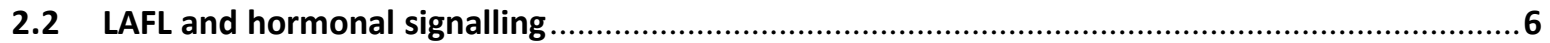

2.3 How the LAFL maintain embryogenic cell fate and repress vegetative development .............7

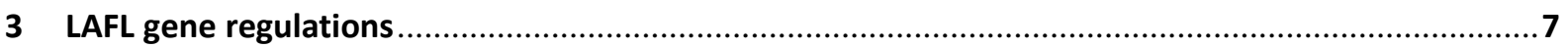

3.1 Multiple transcriptional feedback regulations ............................................................

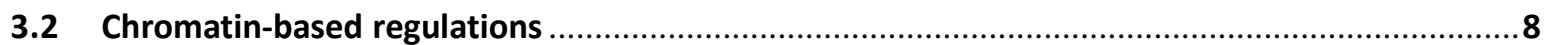

3.3 Structure function relationships of $L A F L$ promoters .................................................11

3.4 Post-transcriptional and post-translational regulations ................................................ 13

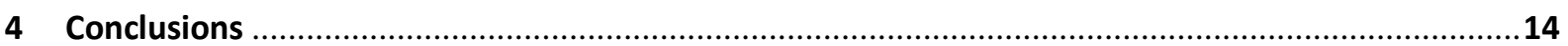

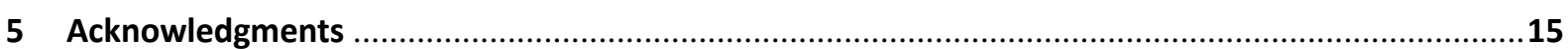

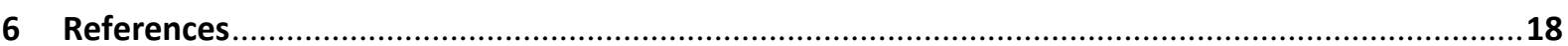




\subsection{Structure, evolution, and expression of the LAFL genes}

The few hundred genes highly and specifically expressed during the different phases of seed development (e.g. embryogenesis, maturation, and acquisition of desiccation tolerance and dormancy) emphasize the importance of transcriptional regulations for proper seed formation (Harada and Pelletier, 2012). The LAFL genes namely LEC1, ABI3, FUS3, and LEC2, encode master transcriptional regulators that induce and maintain these different phases of seed development and repress precocious seed germination and vegetative growth in Arabidopsis (Braybrook and Harada, 2008; Santos-Mendoza et al., 2008; Verdier and Thompson, 2008; Roscoe et al., 2015; Carbonero et al., 2016; Fatihi et al., 2016; Gonzalez-Morales et al., 2016; Boulard et al., 2017). LEC1 (LEEAFY COTYLEDON1) is a member of the NF-YB protein family (NF-YB9, HAP3 subunit of the CCAAT-box binding factors) and has a closely related homolog LEC1-like (L1L, NF-YB6) (Lotan et al., 1998; Kwong et al., 2003; Zhao et al., 2016; Boulard et al., 2017; Swain et al., 2017). ABI3 (ABSCISIC ACID INSENSITIVE3), FUS3 (FUSCA3), and LEC2 (LEAFY COTYLEDON2) belong to the plant specific family of B3 domain Transcription Factors (TFS) and thus are also named "AFL-B3" regulators (Giraudat et al., 1992; Baumlein et al., 1994; Keith et al., 1994; Luerssen et al., 1998; Stone et al., 2008; Swaminathan et al., 2008; Carbonero et al., 2016; Devic and Roscoe, 2016; Fatihi et al., 2016; Boulard et al., 2017; Lehti-Shiu et al., 2017).

Homologs of LEC1, $A B 13$, and FUS3 have been identified in all the angiosperms studied so far, including important crops such as rice, maize, wheat, soybean, or barley (Verdier and Thompson, 2008; Wang et al., 2012; Peng and Weselake, 2013; Cagliari et al., 2014; Carbonero et al., 2016; Fatihi et al., 2016; Boulard et al., 2017; Manan et al., 2017; Pelletier et al., 2017; Sun et al., 2017; Zhiguo et al., 2018). Some of these homologs have been functionally characterized in monocots, and in lower plants, such as $A B I 3$ in the moss $P$. patens (Tan et al., 2017). LEC2 seems to be found only in dicots (Li et al. 2010). Although the existence of $L E C 2$ orthologs in monocots has been suggested based on sequence similarity, their function might be slightly different (e.g. ZmAFL4, which is expressed in maize endosperm and involved in carbon metabolism and starch accumulation) or remains to be investigated (Grimault et al., 2015; Carbonero et al., 2016; Boulard et al., 2017). Moreover, another LEC2 related sequence specific to monocot, namely "IDEF", has been describes and could be a monocot ortholog (Li et al., 2010). As things stand, it is therefore unclear whether LEC2 arose from a duplication of $A B I 3$ in dicots after the divergence of monocots and dicots, or if gene duplication occurred before this divergence, with rapid evolution or loss of $L E C 2$ in monocots. Moreover, $A B I 3$, which is the putative common ancestor of the AFL-B3 (Li et al., 2010), shares some functional similarities with LEC2 (Baud et al., 2016). As a consequence, $L E C 2$ may be dispensable in most plants where $A B / 3$ or some closely related proteins could fulfil similar function.

The expression patterns of the LAFL genes have been extensively described in Arabidopsis (Lotan et al., 1998; Kwong et al., 2003; Gazzarrini et al., 2004; Ng et al., 2004; To et al., 2006; Santos-Mendoza et al., 2008; Sreenivasulu and Wobus, 2013; Roscoe et al., 2015; Boulard et al., 2017; Tao et al., 2017). LAFL are expressed in seed and, under normal physiological conditions, none of the mRNAs is 
detected above the background noise outside of the seed (http://bar.utoronto.ca). Nevertheless, a few studies report some LAFL promoter activity in vegetative tissues and abnormal vegetative phenotypes of lafl mutants. FUS3 and LEC2 could be involved in lateral root formation (Tang et al., 2017) and LEC1 in hypocotyl elongation in dark-grown seedlings (Junker and Baumlein, 2012; Huang et al., 2015a). More recently, it has been demonstrated that LEC1 plays a role in the activation of the flowering gene $F L C$, but also that $L E C 1$ is expressed only in seed and induces $F L C$ early during embryo development (Tao et al., 2017). Thus, the activation of LAFLS during vegetative development may be restricted to specific cells or stress conditions such as wounding or skotomorphogenesis (Junker et al., 2012; Huang et al., 2015b; Iwase et al., 2015; Swain et al., 2017). In Arabidopsis seed, LAFL mRNAs are detected early during embryo development: $L E C 1$ and $L E C 2$ peak about a week after pollination, whereas $A B I 3, F U S 3$, and L1L peak one week later. It is to be noted that FUS3 would be mainly expressed in the epidermis (Gazzarrini et al., 2004; Tsuchiya et al., 2004). These specific and overlapping expression patterns are fully consistent with the partial redundancy of the LAFL described below. The LAFL transcripts are also detected in the endosperm although metabolic and developmental fates are different from that of the embryo. It suggests that additional regulators are required to specify the proper accumulation of different storage compounds in the two zygotic tissues.

\subsection{Redundant and partially overlapping functions in controlling seed development}

Genetic analyses have revealed the partially overlapping and synergistic functions of the LAFL genes during seed development (Raz et al., 2001; To et al., 2006; Braybrook and Harada, 2008; SantosMendoza et al., 2008; Verdier and Thompson, 2008; Yamamoto et al., 2014; Roscoe et al., 2015; Carbonero et al., 2016). The lafl mutants are all affected in seed reserve deposition, but the severity of the phenotypes increases in double and triple mutants, suggesting redundancy and synergism among the LAFL proteins. Consistently, the LAFL share several common targets(Yamamoto et al., 2010; Chiu et al., 2012; Monke et al., 2012; Wang and Perry, 2013; Baud et al., 2016). Moreover, effective complementation of either combinations of double mutants or the triple mutants by expression of individual $A F L-B 3$ confirms a functional redundancy among these regulators (To et al., 2006; Roscoe et al., 2015).

Nevertheless, clear differences have been reported in the level and specificity of the control exerted by each LAFL over the accumulation of fatty acid (FA), triacylglycerols (oil), and storage proteins, vascular differentiation, flavonoid and chlorophyll degradation, or desiccation tolerance for instance (Parcy et al., 1997; Lopez-Molina et al., 2002; Vicente-Carbajosa and Carbonero, 2005; Braybrook et al., 2006; To et al., 2006; Braybrook and Harada, 2008; Santos-Mendoza et al., 2008; Verdier and Thompson, 2008; Monke et al., 2012; Delmas et al., 2013; Yamamoto et al., 2014; Roscoe et al., 2015; Carbonero et al., 2016). That some ectopically expressed individual AFL-B3 essentially restores reserve accumulation and morphology to afl embryos but not tolerance to desiccation nor dormancy also reveals that mid- and late-maturation programs are uncoupled and under the control of distinct LAFL. Conversely, failure to complement single afl mutants may also be due to aberrant vegetative development as a consequence of an excess of AFL factors (Roscoe et al., 2015). Taken together 
these results suggest the existence of upper and lower thresholds of AFL-B3 pool required for proper seed development. Thus, although conservation of the B3 DNA-binding domain is essential for determining embryo morphology and accumulation of reserves, functional specialisation among the AFLs is likely to be determined by their distinct expression patterns and combinatorial interactions with other regulators as described hereafter in this review.

Mutations of the LAFL genes not only affect seed maturation but have also a more global developmental impact: the embryo bypasses the maturation phase and immediately enters vegetative development (Raz et al., 2001; Santos-Mendoza et al., 2008; Yamamoto et al., 2014). The cotyledons display characteristic traits of leaves, such as trichome development, anthocyanin accumulation, and precociously develop stomata and xylem elements, hence the name "Leafy Cotyledon" (Meinke, 1992). This diversity of mutant phenotypes could result from this homeotic modification. In lec1, the precocious expression of a seedling specific gene (i.e. PYK10) can be detected very early at the globular-heart transition stage of embryo development, before the activation of seed maturation genes (Yamamoto et al., 2014). This suggests that the heterochronic expression of seedling genes in lec1 embryos is not only a consequence of a defect in the maturation program, but also results from the inability to maintain their repression during early embryogenesis. Consistent with this developmental role, the ectopic expression of LEC1 and LEC2 in vegetative tissues is sufficient to trigger the seed maturation program and somatic embryogenesis, whereas lec1 and lec2 mutants have lower ability to undergo somatic embryogenesis (Lotan et al., 1998; Stone et al., 2001; Gaj et al., 2005; Santos Mendoza et al., 2005; Suzuki et al., 2007; Stone et al., 2008; Gao et al., 2009; Junker and Baumlein, 2012; Feeney et al., 2013; Guo et al., 2013; Jia et al., 2013; Wojcikowska et al., 2013; Jia et al., 2014; Zhang et al., 2014b; Ikeuchi et al., 2015; Nowak and Gaj, 2016; Horstman et al., 2017; Magnani et al., 2017; Mozgova et al., 2017; Wójcik et al., 2017; Lee and Seo, 2018). This LEC1/LEC2 activity probably explains why the induction of the LAFL genes is accurately controlled during seed development and expression strongly repressed during vegetative growth.

\section{Functions of the LAFL proteins}

\subsection{How the LAFL trigger seed maturation}

Induction of seed maturation genes by the LAFL has been extensively analysed and the understanding of the molecular mechanisms involved has considerably progressed recently (Carbonero et al., 2016; Devic and Roscoe, 2016; Fatihi et al., 2016; Boulard et al., 2017). Briefly, the three AFL-B3 proteins bind consensus "RY" DNA motifs (core sequence 5'-CATG-3'), but with different specificities regarding the nucleotides flanking this core sequence. We have recently demonstrated that both LEC2 and ABI3 proteins can cooperate with LEC1 in multi-protein complexes to activate their target promoters (Baud et al., 2016; Boulard et al., 2018). On the contrary, no direct cooperative effect of LEC1 with FUS3 could be demonstrated, suggesting that the molecular mechanisms involving FUS3 are different, unless it requires other cis-DNA sequences and protein partners. 
In addition to RY motifs, the presence of E/G-Box elements (5'-CANNTG-3'/ 5'-CACGTG-3') is also necessary for proper activation of the AFL-B3 target promoters in planta (for references see Abraham et al., 2016; Baud et al., 2016). It suggests that the AFL-B3 can cooperate with bHLH or bZIPs TFs that bind E/G-Box elements (see Plant Transcription Factor Database, http://planttfdb.cbi.pku.edu.cn), as demonstrated for ABI3 with bZIP10/25/53 (Lara et al., 2003; Alonso et al., 2009). In addition, other TFs of the MYB, MADS, DOF or AP2 families are also involved in the activation of maturation genes either as protein partners or as targets mediating the control exerted by the AFL-B3 toward downstream secondary targets. These transcription factors modulate and / or act in combination to specify the function of the LAFL, providing variations in the end-targets of the regulatory cascade and contributing to specify the type of storage compounds accumulated (i.e. oil, starch, or seed storage proteins) in the different zygotic tissues composing the seed (embryo or endosperm). Among the important TF targets of the LAFL are WRINKLED1 (WRI1) and two closely related MYB115/118 genes that play key roles in the regulation of oil deposition, controlling fatty acids biosynthesis and desaturation, respectively (Braybrook et al., 2006; Baud et al., 2009; Wang and Perry, 2013; Troncoso-Ponce et al., 2016; Ettaki et al., 2018).

Finally, the NF-YB LEC1 and L1L can interact with NF-YA and C-subunit proteins, as well as with other proteins including LEC2, ABI3, and some bZIPs (Yamamoto et al., 2009; Boulard et al., 2017; Gnesutta et al., 2017; Boulard et al., 2018). In association with these latter proteins LEC1 binds to genes that are involved in lipid metabolism and hormone signalling (Mu et al., 2008; Yamamoto et al., 2009; Junker et al., 2012; Mendes et al., 2013; Baud et al., 2016). This is consistent with the results of a recent genome-wide survey demonstrating that LEC1 controls distinct gene sets with different cisregulatory elements from early to late stages of seed development (Pelletier et al., 2017).

\subsection{LAFL and hormonal signalling}

One important function of the LAFL relates to various plant hormone metabolisms and/or signalling, (Junker and Baumlein, 2012; Jia et al., 2014). For instance, during embryogenesis, the control of auxin biosynthetic genes by LEC1 and LEC2 could play a role in maintaining or inducing a totipotent cell state (Stone et al., 2008; Wojcikowska et al., 2013; Wójcikowska and Gaj, 2015). FUS3 also interacts with LEC2 to induce auxin biosynthesis during lateral root formation (Tang et al., 2017) and auxin induces FUS3 expression (Gazzarrini et al., 2004) in a positive feedback loop regulation. FUS3 controls the critical $A B A / G A$ balance by repressing $G A$ biosynthesis and by promoting $A B A$ accumulation, whereas $A B I 3$ rather integrates ABA signalling (Curaba et al., 2004; Gazzarrini et al., 2004; Wang et al., 2004; Braybrook et al., 2006).

Moreover, LAFL activities are themselves controlled by hormone signaling through positive or negative feedbacks loop involving $A B A$ and $G A$, respectively. Indeed, $A B A$ has a positive role in the expression of $A B I 3$ (Lopez-Molina et al., 2002; Cheng et al., 2014), while GA has been shown to repress FUS3 expression (Curaba et al., 2004; Gazzarrini et al., 2004; Wang et al., 2004; Braybrook et al., 2006). The transcription factor WRKY41, which induces the expression of $A B I 3$ during seed maturation, is negatively regulated by ABA (Kanno et al., 2010; Ding et al., 2014). In addition, ABA 
and GA modulate $A B I 3$ and FUS3 activity through post-translational regulations (Gazzarrini et al., 2004; Zhang et al., 2005). Last, brassinosteroids are involved in repression of $A B / 3$ expression and weak ABA sensitivity during germination (Ryu et al., 2014).

\subsection{How the LAFL maintain embryogenic cell fate and repress vegetative development}

While the function of the LAFL as positive regulators of seed maturation genes has been well establish their active role in repressing germination, seedling and vegetative development remains to be thoroughly investigated (Yamamoto et al., 2014; Yoshii et al., 2015). As described above, LAFL regulators are involved in the control of the hormonal ABA/GA balance. An elevated ratio such as the one found in embryo promotes maturation, whereas a lower ratio is associated with the activation of seedling development as in lec1 or fus3 (Curaba et al., 2004; Gazzarrini et al., 2004; Yamamoto et al., 2014; Liu and Hou, 2018). Interestingly, the precocious expression of PYK10 observed in lec1 and fus3 embryos is also found in ga deficient backgrounds (i.e. ga1 lec1 and ga1 fus3 double mutants), suggesting that the elevated gibberellin level found in lec1 or fus3 simple mutants is not the cause of the heterochronic gene expression in these mutants (Yamamoto et al., 2014). Moreover, there is no strict overlapping between the timing of LAFL expression and appearance of the abnormal phenotypes in corresponding lafl mutants. These observations together with the stochastic and cellautonomous expression of PYK1O in lafl mutant embryos and modification of the PYK1O locus by histone modifications suggest the involvement of LAFL in epigenetic mechanisms repressing postgermination genes during embryogenesis.

\section{$3 \quad$ LAFL gene regulations}

\subsection{Multiple transcriptional feedback regulations}

Genetic analyses have shown that LAFLs are components of regulatory loops inducing their own expression. LEC1 and LEC2 can activate their own expression as well as the expression of FUS3 and $A B I 3$, depending on the tissue considered (To et al., 2006; Suzuki and McCarty, 2008; Monke et al., 2012; Wang and Perry, 2013; Zhu et al., 2013; Carbonero et al., 2016; Devic and Roscoe, 2016; Fatihi et al., 2016; Boulard et al., 2017; Pelletier et al., 2017). ABI3 and FUS3 also activate their own transcription. These positive feedback regulations probably contribute to enhance the activity of the network during seed development and are consistent with the occurrence of a minimum threshold for AFL-B3 pool to function (Santos-Mendoza et al., 2008; Yamamoto et al., 2014; Devic and Roscoe, 2016).

Several additional transcriptional regulatory feedbacks have been identified that affect the expression of the LAFL genes (Figure 1). For instance, LEC2 and FUS3 activate AGL15 that in turn activates the LAFL genes in a positive loop (Zhu and Perry, 2005; Braybrook et al., 2006; Zheng et al., 2009; Wang and Perry, 2013; Jia et al., 2014). However, this positive feedback loop is limited by the fact that AGL15 negatively regulates its own expression. Moreover, the normal LAFL expression in agl15 mutant seeds (Chen et al., 2018) suggests that paralogous MADS proteins could act redundantly with AGL15 to control the network. Another complex regulation involves the closely 
related MYB115 and MYB118. Their expression is induced by the LAFL in the endosperm of maturing seeds and they repress in turn $L E C 2$ expression in the endosperm. What is more, these MYB trigger LEC1 expression and thus promote somatic embryogenesis when expressed ectopically in vegetative tissues (Wang et al., 2009; Zhang et al., 2009). Nevertheless, neither the myb118 nor the myb118 myb115 double mutants display obvious developmental defects (Troncoso-Ponce et al., 2016), suggesting that genetic redundancy also exists between these TFs. Last, the HD-ZIP transcription factors PHAVOLUTA (PHV) and PHABULOSA (PHB) induce LEC2 during early embryogenesis (Tang et al., 2012b), and BABY BOOM (an APETALA2/ ERE-binding factor) directly binds LAFL gene promoters and activates their expression during somatic embryogenesis (Horstman et al., 2017).

Some negative regulations of the LAFL genes have been characterized too (Figure 1). The trihelix transcription factors ASIL1/2 inhibit LEC2 and FUS3 expression during both early embryogenesis and after germination (Willmann et al., 2011). The homeodomain proteins HIGH-LEVEL EXPRESSION OF SUGAR-INDUCIBLE GENE 2 (HSI2), and HSI2-like1 (HSL1), that have been also referred to as VP1/ABI3Like1 (VAL1) and VAL2, respectively, inhibit the LAFL network in developing seedlings and are required to terminate the embryonic developmental program (Tsukagoshi et al., 2005; Suzuki et al., 2007; Tsukagoshi et al., 2007; Veerappan et al., 2012; Jia et al., 2013; Zhou et al., 2013; Jia et al., 2014; Veerappan et al., 2014; Chhun et al., 2016; Schneider et al., 2016). HSI2 and HSL1 can form homo or heterodimers that can bind promoter regions and inhibit the expression of LAFL and other target genes (Chhun et al., 2016). Nevertheless, recent experiments suggest that the dimers would rather bind AGL15 promoter and indirectly repress the LAFL genes (Chen et al., 2018). Interestingly, FUS3 has been shown to activate HSI2/VAL1 at the end of the maturation phase (Wang and Perry, 2013), triggering its own down regulation. These HSI/VAL proteins contain several domains involved in the interaction with chromatin-modifying proteins or the chromatin itself, highlighting the importance of these regulations for LAFL expression, as described below.

\subsection{Chromatin-based regulations}

Dynamic chromatin modifications and DNA methylation occur during seed development and germination (Muller et al., 2012; Yang et al., 2013; Kawashima and Berger, 2014; Molitor et al., 2014; Bouyer et al., 2017; Kawakatsu et al., 2017; Lin et al., 2017; Narsai et al., 2017). Nevertheless, the significant increase in DNA methylation observed at non-GC sites does not seem to be involved in the control of seed gene expression (Lin et al., 2017). On the contrary, LAFL genes are subject to extensive chromatin modification dynamics and numerous reports provide insight into the mechanisms involved (Figure 2). This is especially evident during the germination process, leading to the silencing of $L A F L$ genes. In mature embryos, $A B I 3$ and $L E C 2$ are associated with H3K4me3, which marks active genes. These marks are replaced by negative H3K27me3 marks upon germination (Muller et al., 2012; Molitor et al., 2014). Hence, removal of histone acetylation (H3ac and/or H4ac), which is associated with active transcription, is a prerequisite to establish and maintain repression. Stable repression is carried out by the Polycomb Repressive Complexes PRC1 and 2 (Mozgova and Hennig, 2015). PRC2 has Histone3 Lysine 27 trimethylase (H3K27me3) activity and PRC1 carries out histone $\mathrm{H} 2 \mathrm{~A}$ Lysine ubiquitination (H2Aub). The canonical role of PRC1 is to recognize H3K27me3 and 
confer chromatin compaction, although this view seems largely oversimplified. For instance, PRC1 also acts independently or upstream of PRC2 in both animals and plants (Gil and O'Loghlen, 2014; Merini and Calonje, 2015). Both PRC1 and PRC2 correspond to several complexes with various specificities and functions depending on protein partners and target genes (Wang et al., 2016; Merini et al., 2017). In addition, LHP1 that has been primarily associated with PRC1 function (Turck et al., 2007; Zhang et al., 2007) was also found to be associated with members of PRC2 (Derkacheva and Hennig, 2014), questioning the explicit separation of both complexes in Arabidopsis. Thus, the relationship between PRC1 and PRC2 may be specific to various complexes and target genes, although both are required for stable repression (Figure 2).

Consistent with the positive role of histone acetylation on LAFL expression, chemical inhibition of histone deacetylase (HDACs) activity and mutations in the closely related HDACS, HDA6 and HDA19, maintain elevated H3K9ac and H4Kac over the $5^{\prime}$ region of the LAFL genes and induce their expression in seedlings (Tanaka et al., 2008; Zhou et al., 2013). Moreover, two other closely related deacetylases (HDA7 and HDA9) negatively regulate seed germination (van Zanten et al., 2014), indicating that HDAC activity is required for both, the termination of seed maturation and the onset of germination programs. HDA19 can be recruited by the brassinosteroid-activated BES1 to repress $A B / 3$ expression during germination (Ryu et al., 2014). HDA6 and HDA19 would also be recruited respectively by VAL1/HSI2 and VAL2/HSL1 that interact with the H3K4me3 marks (Zhou et al., 2013; Chhun et al., 2016; Schneider et al., 2016). As discussed above, HSI2 and HSL1 could repress LAFL genes directly (Chhun et al., 2016) or indirectly through binding to and repression of AGL15 (Chen et al., 2018). Apart from HSI/VAL, the GRAS-transcription factor SCARECROW-LIKE15 (SCL15) has been involved in conveying HDA19 to $A B / 3$ after germination, although the HDA19 binding to $A B I 3$ was unaltered in scl15 mutant seedlings (Gao et al., 2015).

Several proteins involved in histone methylation have been shown to regulate $L A F L$ expression and seed dormancy (Narro-Diego et al., 2017; Nonogaki, 2017). For instance, mutants affected in ATRX7 (H3K4 methyltransferase), EFS/SDG8 (H3K36 di- and trimethylation), EBS (an H3K4me2/3 "reader" interacting with HDA6) or HUB1 and HUB2 ( $\mathrm{H} 2 B$ monoubiquitination) display lower $A B / 3$ expression and dormancy, whereas those affected in H3K9 methylation (kyp/suvh4) or H3K4 demethylation (Idl1 and IdI2) display the opposite phenotype (Liu et al., 2007b; Bassel et al., 2011; Zheng et al., 2012; Zhao et al., 2015; Narro-Diego et al., 2017). Moreover, although PRC1/2 are not required for proper embryo development, mutations affecting PRC1 or PRC2 lead to a failure in both, the repression of LAFL expression and directly switch from embryo to seedling development (Chanvivattana et al., 2004; Makarevich et al., 2006; Aichinger et al., 2009; Bratzel et al., 2010; Chen et al., 2010; Berger et al., 2011; Bouyer et al., 2011; Muller et al., 2012; Tang et al., 2012a; Zhang et al., 2012; Deng et al., 2013; Yang et al., 2013; Molitor et al., 2014; Ikeuchi et al., 2015; Mozgova et al., 2015; Xiao and Wagner, 2015; Feng et al., 2016; Trindade et al., 2017; Xiao et al., 2017; Lee and Seo, 2018). Similar accumulation of seed proteins in vegetative tissues is also observed when the RETINOBLASTOMARELATED1 (RBR1) that is required to maintain the PRC2-dependent repression of $L E C 2$ and $A B I 3$ is affected (Gutzat et al., 2011; Kuwabara and Gruissem, 2014) and in mutant of the SWI2/SNF2 
chromatin remodelling ATPase BRAHMA (BRM) (Tang et al., 2008), although BRM has been shown to controls the transition from juvenile to adult vegetative phase antagonistically to PRC2 (Xu et al., 2016).

PRC1 complexes initiate the repression of the embryonic program allowing H3K27me3 deposition and the establishment of more stable irreversible repression (Calonje, 2014; Mozgova et al., 2015; Xiao and Wagner, 2015; Zhou et al., 2017). LHP1 seems to have only a limited impact on this developmental switch (Wang et al. 2016), despite its binding to $A B / 3$ (Molitor et al. 2014). Besides its interaction with H3K4me3 and HDACs, VAL/HSI and ALFIN1- like (AL) proteins also recruit PRC1 to seed maturation loci such as LEC2 (Bratzel et al., 2010; Yang et al., 2013; Molitor et al., 2014; Questa et al., 2016; Yuan et al., 2016; Merini et al., 2017; Chen et al., 2018; Lee and Seo, 2018). Consistently, hsi2, hsl1/val1, and val2 mutants show reduced H3K27me3 and H2Aub levels at LAFL genes during germination. It is also likely that the PHD domain of HSI2 alone can repress target genes by binding with the repressive H3K27me3 mark (Veerappan et al., 2014). Therefore, this module involving the two PHD-domain proteins HSI2/VAL1 and ALFIN1-like (AL) might directly trigger the switch from an active (H3K4me3 marked) to a repressed, (H3K27me3 marked) state for LAFL genes. However, AL binding to $A B I 3$ was only detected at the end of the germination process (Molitor et al., 2014), suggesting that AL is implicated in maintenance of repression rather than in the initiation of the process.

The key role of HSI2/VAL1 in mediating LAFL silencing is emphasized by its interaction with MSI1 (Mehdi et al., 2016), a WD protein that is thought to bridge PRC1 and PRC2 function (Derkacheva et al., 2013). Beside its association with PRC2 and PRC1, MSI1 is also a member of the histone H3-H4 chaperone CAF1 complex (Ramirez-Parra and Gutierrez, 2007) and it needs to be determined how its association with HDA19 (Mehdi et al., 2016) and HSI2 (Chen et al., 2018) relates to these two distinct functions. PRC2 recruitment involves specific Polycomb Responsive Elements (PREs) that trigger binding of PRC2-associated transcription factors and subsequent H3K27me3 deposition. A first PRE motif named "RLE" (Repressive LEC2 Element) has been identified and functionally characterized, that is responsible for LEC2 stable repression after the embryonic stage (Berger et al., 2011; Xiao et al., 2017). An orthologous sequence has been identified in the FUS3 promoter (Devic $M$, unpublished) suggesting a common regulatory module of PRC2-mediated LAFL repression. The requirement for dynamic chromatin remodeling is further supported by recent reports on the synergistic activity of the normally antagonistically acting EMBRYONIC FLOWER 1 (EMF1) and trithorax group (TrXG) proteins ATX1 and ULT1 (Kim et al., 2012; Xu et al., 2018). Unexpectedly, the loss of TrxG enhances the de-repression of LAFL observed in emf1 single mutants. Although there is no direct correlation with TrXG-associated H3K4me3 levels, both ATX1 and ULT1 bind to LEC2 and $A B I 3$ locus and also interact with EMF1, suggesting a concerted activity to repress LAFL after embryogenesis (Xu et al., 2018). Alternatively, both PcG-dependent repression of embryo-specific transcripts, as well as elevated activation of post-embryonically expressed genes requiring TrxG function might be necessary to efficiently switch from seed to seedling development. This scenario would be in agreement with the highly dynamic chromatin modification changes observed during 
this transition process.

Two ATP-dependent chromatin-remodelling proteins of the CHD3 family PICKLE (PKL) and PKR2 are also involved in the regulation of LAFL expression during germination and in vegetative tissues. The mutants fail to repress LAFL and display reduced H3K27me3 marking during germination (Dean Rider et al., 2003; Henderson et al., 2004; Zhang et al., 2008; Aichinger et al., 2011; Zhang et al., 2012; Han et al., 2015; Carter et al., 2016), emphasizing a requirement for active chromatin remodeling to switch between H3K4me3 and H3K27me3. Importantly, PKL has also been found to negatively regulate $\mathrm{H} 3 \mathrm{~K} 27 \mathrm{me} 3$, underlining its role as nucleosome remodeler instead of being a constitutive polycomb cofactor (Aichinger et al., 2011; Ho et al., 2013; Jing et al., 2013). Moreover, it has been recently demonstrated that PKL significantly affects RNA-directed DNA Methylation (RdDM) at specific target loci, suggesting that it may be required to create a chromatin environment that influences non-coding RNA production, DNA methylation and transcriptional silencing (Yang et al., 2017a). Last, PKL has been implicated in GA signalling (and thus, germination) by interacting with DELLA proteins that are master repressors of GA signalling (Zhang et al., 2014a).

Less information is available about the role of chromatin dynamic in activating LAFL genes during seed development. Nevertheless PKL (CHD3 family) and paralogous CHR5 (CHD1 family) act antagonistically during seed maturation for establishing an active chromatin state allowing proper induction of $A B I 3$ and FUS3 (Shen et al., 2015). In addition, mutations of CLF (which encodes a PRC2 subunit) lead to ectopic expression of AGL15, FUS3, and $A B I 3$ associated with enhanced accumulation of oil in seed (Liu et al., 2016). Moreover, consistent with the chromatin repression of LAFL expression and the role of LEC1 and LEC2 in somatic embryogenesis previously described, mutations affecting PKL or VAL1 induce LAFL expression and improve the efficiency of somatic embryogenesis (Horstman et al., 2017). Similarly mutation affecting FIE an essential component of PRC2, results in abnormal vegetative development that resembles somatic embryogenesis (Bouyer et al., 2011). These results are fully consistent with the simultaneous repression of LAFL expression and loss of zygotyc embryo potential for somatic embryogenesis that occur during germination (Horstman et al., 2017; Mozgova et al., 2017).

\subsection{Structure function relationships of LAFL promoters}

Molecular dissections and functional analyses of promoter regions and the subsequent identification of important cis-elements and trans-acting factors have brought further information on the regulations of $A B I 3$ (Ng et al., 2004) and LEC2 (Berger et al., 2011), but are still missing for FUS3 or LEC1. The promoter region necessary for high and accurate expression of $A B / 3$ is unusually long $(\mathrm{Ng}$ et al., 2004). Fragments of 4.6 or $3.6 \mathrm{~kb}$ upstream the transcription start site, provide the best level of activation. Loss of a further $1.6 \mathrm{~kb}$ results in a severe decrease of promoter activity. Deletion of an additional $1.2 \mathrm{~kb}$ almost completely abolishes $A B / 3$ transcription. Equally, the 5'UTR of $A B / 3$ mRNA of $541 \mathrm{bp}$ (previously estimated at 519 bp) is much longer than the average size of $155 \mathrm{bp}$ for Arabidopsis genes (Srivastava et al., 2018). This sequence has a negative effect on $A B / 3$ expression, probably affecting translation. It has been shown that the homeodomain transcription factors BLH1 
and KNAT3 activate $A B I 3$ gene expression (Kim et al., 2013), whereas RAV1, a TF of the B3-Family represses $A B / 3$ expression upon seed imbibition (Feng et al., 2014). But only a few functional ciselements and their corresponding factors (e.g WRKY41) have been thoroughly characterised in the $A B / 3$ promoter to date (Ding et al., 2014).

All the regulatory elements of the promoter required for proper expression of LEC2 are present within the $447 \mathrm{bp}$ sequence upstream the translation start codon. The developmental regulation of LEC2 expression results from a combination of activating and repressive mechanisms involving at least three distinct cis-regulatory elements located within the proximal LEC2 promoter (Berger et al., 2011). Two of them, a CArG regulatory elements recognized by MADS box transcription factors and a GAGA box bound by plant BPC (BASIC PENTACYSTEINE) proteins are essential for the transcriptional activation of $L E C 2$ during seed development. The third element named RLE (Repressive LEC2 Element) was the first plant functional homolog of a PRE element (Berger et al., 2011). PREs have been extensively characterized in Drosophila and are necessary and sufficient for H3K27me3 deposition and transcriptional repression (Ringrose and Paro, 2007), which also characterizes the RLE. Chromatin Immunoprecipitation (ChIP) experiments suggested that both RLE and GAGA element provide sites for PRC2 binding, although the factor binding these elements remain to be identified (Berger et al., 2011; Deng et al., 2013; Hecker et al., 2015). BPC factors are also necessary for the repressive action of PRC1 (Hecker et al., 2015) and PRC2 (Mu et al., 2017a). In cucumber, BPC factors bind the $A B / 3$ promoter to repress its activity and control seed germination ( $\mathrm{Mu}$ et al., 2017b). The repressive action of BPC together with PRC2 could therefore constitute a widespread mechanism restricting the expression of LAFL to seed development (Mu et al., 2017a).

Similarly, the expression of FUS3 is regulated by positive and negative cis-elements. A $2 \mathrm{~kb}$ upstream sequence of the FUS3 gene contains all the necessary elements allowing proper FUS3 expression and to complement the fus3-3 mutation (Gazzarrini et al., 2004), and a shorter sequence of $500 \mathrm{bp}$ is also sufficient (Roscoe et al. unpublished). Several activating transcription factors directly recognising the promoter have been identified mainly by ChIP (as described above, e.g. AGL15/18, LEC2, or LEC1). Sequences recognised by factors participating in epigenetic regulation of FUS3 have also been characterised. MEDEA, a subunit of PRC2, binds to the promoter of FUS3 on a defined 126 bp fragment (Makarevich et al., 2006). Binding of this PRC2 subunit is thought to repress FUS3 expression in the endosperm. On the contrary, binding of CHR5 around the transcription start site regulates nucleosomes occupancy and enhances FUS3 expression (Shen et al., 2015).

No detailed analyses of the LEC1 promoter have been performed, although a genomic fragment of $3.4 \mathrm{~kb}$, which includes $2.5 \mathrm{~kb}$ of promoter, was sufficient for complementation of the lec1 phenotype (Lotan et al., 1998). On this line, about $2 \mathrm{~kb}$ of $L E C 1$ promoter allowed the complementation of lec1 with L1L (Kwong et al., 2003). To gain further insight into the transcriptional regulations of LAFL expression, the promoter-deletion studies could be combined with a comprehensive mapping of transcription factor-promoter interactions for the four LAFL regulators (Castrillo et al., 2011; Gaudinier et al., 2017). Since there is a positive correlation between the number of TF bound to a 
promoter and its developmental importance, we can expect to identify supplementary TF binding to the LAFL promoters. For example, more than $30 \mathrm{TF}$ recognise the promoters of REV and PHB in comparison to the average number of 3.36 TF per promoter reported in Arabidopsis (Brady et al., 2011; Gaudinier et al., 2011). These results should allow a comparison of the transcriptional regulation of LAFL genes and discriminate the common cis-elements/trans-acting factors from the specific ones.

\subsection{Post-transcriptional and post-translational regulations}

Overall, miRNA are involved in the control of several aspects of plant development, including seed and embryo development (for review see Seefried et al., 2014; D'Ario et al., 2017; Rodrigues and Miguel, 2017). For instance, loss of DICER-LIKE 1 (DCL1), the major RNA helicase involved in miRNA processing leads to embryo lethality (Golden et al., 2002; Park et al., 2002). During early embryogenesis, miR156 represses LEC1, FUS3 and ABI3 expression by silencing SPL10 and SPL11, therefore preventing precocious onset of the maturation program (Nodine and Bartel, 2010; Willmann et al., 2011; Vashisht and Nodine, 2014). It is not clear whether LAFL are direct targets of SPL10/11. The HD-ZIP PHABULOSA (PHB), which recognises cis-elements in the LEC2 promoter, and PHAVOLUTA (PHV) are targets of miR166 (Tang et al., 2012b). It is hypothesised that miR156 could act together with miR166 to repress the maturation phase in the leaves. In addition, miR165/166 together with miR160 (which targets the AUXIN RESPONSE FACTORS ARF10, ARF16, and ARF17) contribute to the control of somatic embryogenesis involving LEC2 (Wójcik et al., 2017) and the repression of ARF10 by miR160 is involved in the regulation of ABA-responsive genes (Liu et al., 2007a). The regulation of LAFL by miRNA is an integral part of the network's feedback regulatory loop. For instance, miRNA156 is activated by FUS3 (Wang and Perry, 2013) as well as AGL15/AGL18 (Serivichyaswat et al., 2015). In return, AGL15/18 activate ABI3, FUS3 and LEC2 (Zheng et al., 2009), but are also activated by FUS3 (Wang and Perry, 2013) and LEC2 (Braybrook et al., 2006).

Alternative splicing has been shown to produce truncated $A B \mid 3$ proteins in numerous species including Arabidopsis, tomato, wheat, rice, pea or flax (McKibbin et al., 2002; Gao et al., 2013; Wang et al., 2018). Developmentally regulated alternative splicing may contribute to a fast inhibition of the seed maturation program in germinating Arabidopsis seed (Sugliani et al., 2010). The mis-splicing of $V P$-1, the wheat $A B I 3$ ortholog, yields truncated polypeptides that could be involved in the susceptibility to pre-harvest sprouting (McKibbin et al 2002). In pea, several $A B \mid 3$ isoforms with different in vitro activity were identified (Gagete et al., 2009; Gao et al., 2013). But in most cases, because $A B I 3$ is a multi-functional protein with several acidic and basic sub domains (A1, B1, B2, B3), the biological significance of $A B I 3$ alternative splicing remains to be further investigated.

Last, posttranslational controls involving protein phosphorylation and ubiquitination play an important role in hormone signalling, including ABA (for review see Yang et al., 2017b). Among the LAFL, $A B I 3$ and FUS3 have been shown to be short-lived proteins. $A B I 3$ is ubiquitinated after interaction with ABI3-INTERACTING PROTEIN 2 (AIP2) E3 ligase and subsequently degraded by the proteasome (Zhang et al., 2005). FUS3 contain a C-terminal PEST domain necessary for targeting to 
degradation and for FUS3 function, since C-terminal truncated FUS3 is unable to complement the fus3 phenotype (Lu et al., 2010). On the contrary, when phosphorylated at the $\mathrm{N}$-terminus by AKIN10, FUS3 is stabilised (Tsai and Gazzarrini, 2012). This phosphorylation of FUS3 is necessary for proper embryogenesis and integration of environmental cues (Chan et al., 2017). FUS3 also interacts with AIP2 leading to its degradation during early embryogenesis preferentially in the protoderm (Duong et al., 2017). Altogether, these positive and negative post-translational mechanisms allow a rapid adjustment of the protein level within the cell. At present, it is not known whether LEC1 and LEC2 stability are also regulated.

\section{$4 \quad$ Conclusions}

The LAFL regulators fulfil crucial functions in angiosperms promoting embryogenesis and seed maturation, and preventing precocious germination. These multiple roles of the LAFL directly activating maturation genes, maintaining embryonic cell fate and repressing vegetative growth, and their partial functional redundancy with intricate cross-talks and feedback loop regulations have hampered the elucidation of the underlying molecular mechanisms. Recent progress has been made by combining various genetic, molecular, cellular, in vivo, and in vitro approaches. However, our understanding of the network remains limited by the paucity of information available on the spatiotemporality of these multiple controls. It is crucial to apply novel approaches to monitor the molecular events (i.e. chromatin and transcriptome profiling, proteins interactions, hormone levels) directly within the seed, in a cell-specific manner. Recent developments combining INTACT or laserassisted micro-dissection with RNA-seq, ATAC- and CHIP-seq (Belmonte et al., 2013; Buenrostro et al., 2015; Chan et al., 2016; Kelsey et al., 2017; Libault et al., 2017; Magnani et al., 2017; Sakai et al., 2018; Sijacic et al., 2018) may provide more precise and quantitative data to draw a comprehensive and predictive model of the LAFL network.

Consistent with the key functions of the LAFL regulators, their activity is tightly controlled by numerous epigenetic, transcriptional, post-transcriptional and post-translational regulators. This is well exemplified at the transcriptional level, by the co-existence of positive and negative regulatory elements in the promoter of LEC2 and FUS3 that provides robust transcriptional control based on competition between activating and repressing complexes. Altogether, these mechanisms finely tune LAFL activity throughout seed development (i.e. the strong and cell specific expression in the embryo followed by an inhibition during late maturation and vegetative growth). It would be interesting to investigate whether the LAFL network or any of its components respond to environmental changes, and possible participate to seed resilience to biotic or abiotic stresses. This could provide interesting targets for crop improvement under current climate change (Fatihi et al., 2016).

Although it is well established that LAFL repression is accompanied by elevated chromatin dynamics, this picture has been derived mainly from studies in post-embryonic tissues and we still lack information how and when the repression is initiated during the seed maturation phase. Moreover, 
little is currently known about the role of chromatin modifying mechanisms that are involved in LAFL activation during embryogenesis. Thus, it would be interesting to further investigate the epistatic relationship between LAFL and chromatin regulators, by establishing mutant combinations and monitoring their phenotypic and molecular consequences. In addition, it may be of interest to use inducible alleles of LAFL or chromatin regulators, allowing to ectopically activating wild-type or dominant negative regulators, to precisely dissect their role with clear temporal resolution.

Several results suggest that LEC1 and LEC2 may act both, as direct transcriptional activators and as pioneer factors (Mayran and Drouin, 2018; Zaret, 2018) able to trigger chromatin modifications and binding of different TFs. Indeed, LEC1 and LEC2 have homeotic functions often associated with chromatin modifications: they maintain embryonic cell fate and repressed precocious expression of seedling genes (e.g. PYK10), their ectopic expression is sufficient to trigger somatic embryogenesis, and $L E C 2$ is involved in the maturation program triggered in prc2 mutant (Ikeuchi et al., 2015). Moreover, several LEC1/LEC2 target genes (e.g. FUS3 or ABI3) contain PREs and/or are induced in prc mutants (Merini et al., 2017; Xiao et al., 2017), and PRC1 and VAL1/2 co-regulate a high number of genes the promoters of which are significantly enriched in both RY and G-box elements (Wang et al., 2016; Merini et al., 2017) found in LEC1/LEC2 target promoters.

Different NF-Y complexes have been shown to act as pioneer factors in animals or in plants (Hou et al., 2014; Belluti et al., 2018). Therefore, LEC1, as component of NF-Y complexes, may act as pioneer TFs in diverse developmental processes (Pelletier et al., 2017). This hypothesis has been recently nicely supported by the discovery that LEC1 promotes the initial establishment of an active chromatin state at a flowering locus ( $F L C$ ) during early embryo development (Tao et al., 2017). LEC1 directly binds $F L C$, promotes H3K4me3 and H3K36me3 deposition and inhibits antagonist H3K27me3 by engaging EFS/SDG8 and SWRIc, a chromatin remodelling complex (Tao et al., 2017). This conclusion is fully consistent with the lower expression of $A B I 3$ (a LEC1 target) observed in sdg8 mutant. In addition, it has been shown that FLC is also regulated by PRC1 and VAL1/VAL2 (Questa et al., 2016; Yuan et al., 2016).

Taken together these results strongly support that LEC1 and possibly LEC2 act as pioneering factors by direct binding to DNA and recruiting different chromatin regulators that remain to be characterized. Last, VAL1 and RING1b (encoding a PRC1 subunit) are direct targets of FUS3 (Wang and Perry, 2013) and PKL expression is enhanced when LEC1 is over-expressed ( $\mathrm{Mu}$ et al., 2008), suggesting that LAFL could have a role in inducing the chromatin negative feedback regulation of their own expression, at the end of the maturation phase.

\section{$5 \quad$ Acknowledgments}

We apologize to all our colleagues whose works and original articles could not be cited because of space limitations. The IJPB benefits from the support of the Labex Saclay Plant Sciences- SPS (ANR10-LABX-0040-SPS). The collaboration between the authors was supported by the CERES project 
(ANR-10-BLAN-1238). We thank our colleagues D. De Vos, D. Grain, M. Miquel, J. Thévenin, and A. To for their valuable support to the work presented. 


\section{Figure Legends}

Figure 1 Overview of the dynamic regulation of LAFL gene expression. Brown and green boxes contain activators and inhibitors of LAFL genes, respectively. They are grouped according to demonstrated genetic or molecular interactions or functions (target genes, signalling pathways). Arrows indicate demonstrated or putative sequential order of activity during seed development. Details and references are given in the text.

Figure 2. Chromatin based mechanisms of LAFL silencing. Model describing interactions at the LAFL gene location, leading form a transcriptionally active state (H3K4me3 and $\mathrm{H} 3 / \mathrm{H} 4 \mathrm{ac}$ marked) to a repressed state (H3K27me3 marked). The VAL1/2 B3 domain transcription factor has DNA-sequence specific binding activity and contains repressory as well as a PHD chromatin binding domain and serves as a hub to recruit chromatin modifying components, such as HDACs as well as PRC1 and PRC2 components (red colour key). Recruitment of PRC1 to LAFLS is also mediated by the H3K4me3 binding AL PHD domain protein. EMF1, a PRC1/2 co-factor interacts with the TrXG proteins ULT1 and ATX1 (H3K4me3 mediating activity not shown for LAFLS), which synergistically add to H3K27me3 (PRC2)-mediated LAFL repression. The CHD chromatin remodeller PKL is able to shift nucleosome position and possibly involved in changing chromatin conformation. Once repression is established, H3K27me3 and H2Aub (PRC1-mark) are stably maintained and the repressive complex is permanently bound. 
References

Abraham, Z., Iglesias Fernandez, R., Martinez, M., Rubio-Somoza, I., Diaz, I., Carbonero, P., and Vicente-Carbajosa, J. (2016). A developmental switch of gene expression in the barley seed mediated by HvVP1 (Viviparous1) and HvGAMYB interactions. Plant Physiol. 170, 2146-2158.

Aichinger, E., Villar, C.B., Di Mambro, R., Sabatini, S., and Kohler, C. (2011). The CHD3 chromatin remodeler PICKLE and polycomb group proteins antagonistically regulate meristem activity in the Arabidopsis root. Plant Cell 23, 1047-1060.

Aichinger, E., Villar, C.B., Farrona, S., Reyes, J.C., Hennig, L., and Kohler, C. (2009). CHD3 proteins and polycomb group proteins antagonistically determine cell identity in Arabidopsis. PLoS Genet 5, e1000605.

Alonso, R., Onate-Sanchez, L., Weltmeier, F., Ehlert, A., Diaz, I., Dietrich, K., VicenteCarbajosa, J., and Droge-Laser, W. (2009). A pivotal role of the basic leucine zipper transcription factor bZIP53 in the regulation of Arabidopsis seed maturation gene expression based on heterodimerization and protein complex formation. Plant Cell 21, 1747-1761.

Bassel, G.W., Lan, H., Glaab, E., Gibbs, D.J., Gerjets, T., Krasnogor, N., Bonner, A.J., Holdsworth, M.J., and Provart, N.J. (2011). Genome-wide network model capturing seed germination reveals coordinated regulation of plant cellular phase transitions. Proc Natl Acad Sci U S A 108, 9709-9714.

Baud, S., Wuilleme, S., To, A., Rochat, C., and Lepiniec, L. (2009). Role of WRINKLED1 in the transcriptional regulation of glycolytic and fatty acid biosynthetic genes in Arabidopsis. Plant Journal 60, 933-947.

Baud, S., Kelemen, Z., Thevenin, J., Boulard, C., Blanchet, S., To, A., Payre, M., Berger, N., Effroy-Cuzzi, D., Franco-Zorrilla, J.M., Godoy, M., Solano, R., Thevenon, E., Parcy, F., Lepiniec, L., and Dubreucq, B. (2016). Deciphering the Molecular Mechanisms Underpinning the Transcriptional Control of Gene Expression by Master Transcriptional Regulators in Arabidopsis Seed. Plant Physiol 171, 1099-1112.

Baumlein, H., Misera, S., Luerssen, H., Kolle, K., Horstmann, C., Wobus, U., and Muller, A.J. (1994). The FUS3 gene of Arabidopsis thaliana is a regulator of gene expression during late embryogenesis. Plant J. 6, 379-387.

Belluti, S., Semeghini, V., Basile, V., Rigillo, G., Salsi, V., Genovese, F., Dolfini, D., and Imbriano, C. (2018). An autoregulatory loop controls the expression of the transcription factor NFY. Biochim Biophys Acta.

Belmonte, M.F., Kirkbride, R.C., Stone, S.L., Pelletier, J.M., Bui, A.Q., Yeung, E.C., Hashimoto, M., Fei, J., Harada, C.M., Munoz, M.D., Le, B.H., Drews, G.N., Brady, S.M., Goldberg, R.B., and Harada, J.J. (2013). Comprehensive developmental profiles of gene activity in regions and subregions of the Arabidopsis seed. Proc. Natl. Acad. Sci. USA 110, 435-444.

Berger, N., Dubreucq, B., Roudier, F., Dubos, C., and Lepiniec, L. (2011). Transcriptional Regulation of Arabidopsis LEAFY COTYLEDON2 Involves RLE, a cis-Element That Regulates Trimethylation of Histone H3 at Lysine-27. Plant Cell 23, 4065-4078.

Boulard, C., Fatihi, A., Lepiniec, L., and Dubreucq, B. (2017). Regulation and evolution of the interaction of the seed B3 transcription factors with NF-Y subunits. Biochim Biophys Acta 1860, 1069-1078.

Boulard, C., Thévenin, J., Tranquet, O., Laporte, V., Lepiniec, L., and Dubreucq, B. (2018). LEC1 (NF-YB9) directly interacts with LEC2 to control gene expression in seed. Biochim Biophys Acta in press.

Bouyer, D., Kramdi, A., Kassam, M., Heese, M., Schnittger, A., Roudier, F., and Colot, V. (2017). DNA methylation dynamics during early plant life. Genome Biol 18, 179.

Bouyer, D., Roudier, F., Heese, M., Andersen, E.D., Gey, D., Nowack, M.K., Goodrich, J., Renou, J.P., Grini, P.E., Colot, V., and Schnittger, A. (2011). Polycomb repressive complex 2 controls the embryo-to-seedling phase transition. PLoS Genet 7, e1002014. 
Brady, S.M., Zhang, L., Megraw, M., Martinez, N.J., Jiang, E., Yi, C.S., Liu, W., Zeng, A., TaylorTeeples, M., Kim, D., Ahnert, S., Ohler, U., Ware, D., Walhout, A.J., and Benfey, P.N. (2011). A stele-enriched gene regulatory network in the Arabidopsis root. Mol Syst Biol 7, 459.

Bratzel, F., Lopez-Torrejon, G., Koch, M., Del Pozo, J.C., and Calonje, M. (2010). Keeping cell identity in Arabidopsis requires PRC1 RING-finger homologs that catalyze H2A monoubiquitination. Curr Biol 20, 1853-1859.

Braybrook, S.A., and Harada, J.J. (2008). LECs go crazy in embryo development. Trends Plant Sci. 13, 624-630.

Braybrook, S.A., Stone, S.L., Park, S., Bui, A.Q., Le, B.H., Fischer, R.L., Goldberg, R.B., and Harada, J.J. (2006). Genes directly regulated by LEAFY COTYLEDON2 provide insight into the control of embryo maturation and somatic embryogenesis. Proc. Natl. Acad. Sci. USA 103, 34683473.

Buenrostro, J.D., Wu, B., Chang, H.Y., and Greenleaf, W.J. (2015). ATAC-seq: A Method for Assaying Chromatin Accessibility Genome-Wide. Curr Protoc Mol Biol 109, 2129 21-29.

Cagliari, A., Turchetto-Zolet, A.C., Korbes, A.P., Maraschin Fdos, S., Margis, R., and MargisPinheiro, M. (2014). New insights on the evolution of Leafy cotyledon1 (LEC1) type genes in vascular plants. Genomics 103, 380-387.

Calonje, M. (2014). PRC1 marks the difference in plant PcG repression. Mol Plant 7, 459-471.

Carbonero, P., Iglesias-Fernandez, R., and Vicente-Carbajosa, J. (2016). The AFL subfamily of B3 transcription factors: evolution and function in angiosperm seeds. J Exp Bot.

Carter, B., Henderson, J.T., Svedin, E., Fiers, M., McCarthy, K., Smith, A., Guo, C., Bishop, B., Zhang, H., Riksen, T., Shockley, A., Dilkes, B.P., Boutilier, K., and Ogas, J. (2016). Crosstalk between sporophyte and gametophyte generations is promoted by chd3 chromatin remodelers in arabidopsis thaliana. Genetics, DOI: 10.1534/genetics.1115.180141.

Castrillo, G., Turck, F., Leveugle, M., Lecharny, A., Carbonero, P., Coupland, G., Paz-Ares, J., and Onate-Sanchez, L. (2011). Speeding cis-trans regulation discovery by phylogenomic analyses coupled with screenings of an arrayed library of Arabidopsis transcription factors. PLoS One 6, e21524.

Chan, A., Carianopol, C., Tsai, A.Y., Varathanajah, K., Chiu, R.S., and Gazzarrini, S. (2017). SnRK1 phosphorylation of FUSCA3 positively regulates embryogenesis, seed yield, and plant growth at high temperature in Arabidopsis. J Exp Bot 68, 4219-4231.

Chan, A.C., Khan, D., Girard, I.J., Becker, M.G., Millar, J.L., Sytnik, D., and Belmonte, M.F. (2016). Tissue-specific laser microdissection of the Brassica napus funiculus improves gene discovery and spatial identification of biological processes. Journal of Experimental Botany 67, 35613571.

Chanvivattana, Y., Bishopp, A., Schubert, D., Stock, C., Moon, Y.-H., Sung, Z.R., and Goodrich, J. (2004). Interaction of Polycomb-group proteins controlling flowering in Arabidopsis. Development 131, 5263-5276.

Chen, D., Molitor, A., Liu, C., and Shen, W.H. (2010). The Arabidopsis PRC1-like ring-finger proteins are necessary for repression of embryonic traits during vegetative growth. Cell Res 20, 1332-1344.

Chen, N., Veerappan, V., Abdelmageed, H., Kang, M., and Allen, R.D. (2018). HSI2/VAL1 Silences AGL15 to Regulate the Developmental Transition from Seed Maturation to Vegetative Growth in Arabidopsis. Plant Cell 30, 600-619.

Cheng, Z.J., Zhao, X.Y., Shao, X.X., Wang, F., Zhou, C., Liu, Y.G., Zhang, Y., and Zhang, X.S. (2014). Abscisic acid regulates early seed development in Arabidopsis by ABI5-mediated transcription of SHORT HYPOCOTYL UNDER BLUE1. Plant Cell 26, 1053-1068.

Chhun, T., Chong, S.Y., Park, B.S., Wong, E.C., Yin, J.L., Kim, M., and Chua, N.H. (2016). HSI2 Repressor Recruits MED13 and HDA6 to Down-Regulate Seed Maturation Gene Expression Directly During Arabidopsis Early Seedling Growth. Plant Cell Physiol 57, 1689-1706.

Chiu, R.S., Nahal, H., Provart, N.J., and Gazzarrini, S. (2012). The role of the Arabidopsis FUSCA3 transcription factor during inhibition of seed germination at high temperature. BMC Plant Biol 12, 15.

Curaba, J., Moritz, T., Blervaque, R., Parcy, F., Raz, V., Herzog, M., and Vachon, G. (2004). AtGA3ox2, a Key Gene Responsible for Bioactive Gibberellin Biosynthesis, Is Regulated during 
Embryogenesis by LEAFY COTYLEDON2 and FUSCA3 in Arabidopsis. Plant Physiol., pp.104.047266.

D'Ario, M., Griffiths-Jones, S., and Kim, M. (2017). Small RNAs: Big Impact on Plant Development. Trends Plant Sci.

Dean Rider, S., Jr., Henderson, J.T., Jerome, R.E., Edenberg, H.J., Romero-Severson, J., and Ogas, J. (2003). Coordinate repression of regulators of embryonic identity by PICKLE during germination in Arabidopsis. Plant J 35, 33-43.

Delmas, F., Sankaranarayanan, S., Deb, S., Widdup, E., Bournonville, C., Bollier, N., Northey, J.G., McCourt, P., and Samuel, M.A. (2013). ABI3 controls embryo degreening through Mendel's I locus. Proc. Natl. Acad. Sci. USA 110, 3888-3894.

Deng, W., Buzas, D.M., Ying, H., Robertson, M., Taylor, J., Peacock, W.J., Dennis, E.S., and Helliwell, C. (2013). Arabidopsis Polycomb Repressive Complex 2 binding sites contain putative GAGA factor binding motifs within coding regions of genes. BMC Genomics 14, 593.

Derkacheva, M., and Hennig, L. (2014). Variations on a theme: Polycomb group proteins in plants. J Exp Bot 65, 2769-2784.

Derkacheva, M., Steinbach, Y., Wildhaber, T., Mozgova, I., Mahrez, W., Nanni, P., Bischof, S., Gruissem, W., and Hennig, L. (2013). Arabidopsis MSI1 connects LHP1 to PRC2 complexes. EMBO J 32, 2073-2085.

Devic, M., and Roscoe, T. (2016). Seed maturation: Simplification of control networks in plants. Plant Sci 252, 335-346.

Ding, Z.J., Yan, J.Y., Li, G.X., Wu, Z.C., Zhang, S.Q., and Zheng, S.J. (2014). WRKY41 controls Arabidopsis seed dormancy via direct regulation of ABI3 transcript levels not downstream of ABA. Plant J 79, 810-823.

Duong, S., Vonapartis, E., Li, C.Y., Patel, S., and Gazzarrini, S. (2017). The E3 ligase ABI3INTERACTING PROTEIN2 negatively regulates FUSCA3 and plays a role in cotyledon development in Arabidopsis thaliana. J Exp Bot 68, 1555-1567.

Ettaki, H., Troncoso-Ponce, M.A., To, A., Barthole, G., Lepiniec, L., and Baud, S. (2018). Overexpression of MYB115, AAD2, or AAD3 in Arabidopsis thaliana seeds yields contrasting omega-7 contents. PLoS One 13, e0192156.

Fatihi, A., Boulard, C., Bouyer, D., Baud, S., Dubreucq, B., and Lepiniec, L. (2016). Deciphering and modifying LAFL transcriptional regulatory network in seed for improving yield and quality of storage compounds. Plant Sci 250, 198-204.

Feeney, M., Frigerio, L., Cui, Y., and Menassa, R. (2013). Following vegetative to embryonic cellular changes in leaves of Arabidopsis overexpressing LEAFY COTYLEDON2. Plant Physiol 162, 1881-1896.

Feng, C.Z., Chen, Y., Wang, C., Kong, Y.H., Wu, W.H., and Chen, Y.F. (2014). Arabidopsis RAV1 transcription factor, phosphorylated by SnRK2 kinases, regulates the expression of ABI3, ABI4, and ABI5 during seed germination and early seedling development. Plant J 80, 654-668.

Feng, J., Chen, D., Berr, A., and Shen, W.H. (2016). ZRF1 Chromatin Regulators Have Polycomb Silencing and Independent Roles in Development. Plant Physiol 172, 1746-1759.

Gagete, A.P., Riera, M., Franco, L., and Rodrigo, M.I. (2009). Functional analysis of the isoforms of an ABI3-like factor of Pisum sativum generated by alternative splicing. J Exp Bot 60, 17031714.

Gaj, M., Zhang, S., Harada, J., and Lemaux, P. (2005). Leafy cotyledon genes are essential for induction of somatic embryogenesis of $\langle i>$ Arabidopsis $</ i>$. Planta 222, 977-988.

Gao, M.J., Lydiate, D.J., Li, X., Lui, H., Gjetvaj, B., Hegedus, D.D., and Rozwadowski, K. (2009). Repression of seed maturation genes by a trihelix transcriptional repressor in Arabidopsis seedlings. Plant Cell 21, 54-71.

Gao, M.J., Li, X., Huang, J., Gropp, G.M., Gjetvaj, B., Lindsay, D.L., Wei, S., Coutu, C., Chen, Z., Wan, X.C., Hannoufa, A., Lydiate, D.J., Gruber, M.Y., Chen, Z.J., and Hegedus, D.D. (2015). SCARECROW-LIKE15 interacts with HISTONE DEACETYLASE19 and is essential for repressing the seed maturation programme. Nat Commun 6, 7243.

Gao, Y., Liu, J., Zhang, Z., Sun, X., Zhang, N., Fan, J., Niu, X., Xiao, F., and Liu, Y. (2013). Functional characterization of two alternatively spliced transcripts of tomato ABSCISIC ACID INSENSITIVE3 (ABI3) gene. Plant Mol Biol 82, 131-145. 
Gaudinier, A., Tang, M., Bagman, A.M., and Brady, S.M. (2017). Identification of Protein-DNA Interactions Using Enhanced Yeast One-Hybrid Assays and a Semiautomated Approach. Methods Mol Biol 1610, 187-215.

Gaudinier, A., Zhang, L., Reece-Hoyes, J.S., Taylor-Teeples, M., Pu, L., Liu, Z., Breton, G., Pruneda-Paz, J.L., Kim, D., Kay, S.A., Walhout, A.J., Ware, D., and Brady, S.M. (2011). Enhanced Y1H assays for Arabidopsis. Nat Methods 8, 1053-1055.

Gazzarrini, S., Tsuchiya, Y., Lumba, S., Okamoto, M., and McCourt, P. (2004). The transcription factor FUSCA3 controls developmental timing in Arabidopsis through the hormones gibberellin and abscisic acid. Dev.Cell, 373-385.

Gil, J., and O'Loghlen, A. (2014). PRC1 complex diversity: where is it taking us? Trends Cell Biol 24, 632-641.

Giraudat, J., Hauge, B.M., Valon, C., Smalle, J., Parcy, F., and Goodman, H.M. (1992). Isolation of the Arabidopsis ABI3 gene by positional cloning. Plant Cell 4, 1251-1261.

Gnesutta, N., Saad, D., Chaves-Sanjuan, A., Mantovani, R., and Nardini, M. (2017). Crystal Structure of the Arabidopsis thaliana L1L/NF-YC3 Histone-fold Dimer Reveals Specificities of the LEC1 Family of NF-Y Subunits in Plants. Mol Plant 10, 645-648.

Golden, T.A., Schauer, S.E., Lang, J.D., Pien, S., Mushegian, A.R., Grossniklaus, U., Meinke, D.W., and Ray, A. (2002). Short Integuments1/suspensor1/carpel Factory, a Dicer Homolog, Is a Maternal Effect Gene Required for Embryo Development in Arabidopsis. Plant Physiol. 130, 808822.

Gonzalez-Morales, S.I., Chavez-Montes, R.A., Hayano-Kanashiro, C., Alejo-Jacuinde, G., RicoCambron, T.Y., de Folter, S., and Herrera-Estrella, L. (2016). Regulatory network analysis reveals novel regulators of seed desiccation tolerance in Arabidopsis thaliana. Proc Natl Acad Sci U S A 113, E5232-5241.

Grimault, A., Gendrot, G., Chaignon, S., Gilard, F., Tcherkez, G., Thevenin, J., Dubreucq, B., Depege-Fargeix, N., and Rogowsky, P.M. (2015). Role of B3 domain transcription factors of the AFL family in maize kernel filling. Plant Sci. 236, 116-125.

Guo, F., Liu, C., Xia, H., Bi, Y., Zhao, C., Zhao, S., Hou, L., Li, F., and Wang, X. (2013). Induced expression of AtLEC1 and AtLEC2 differentially promotes somatic embryogenesis in transgenic tobacco plants. PLoS One 8, e71714.

Gutzat, R., Borghi, L., Futterer, J., Bischof, S., Laizet, Y., Hennig, L., Feil, R., Lunn, J., and Gruissem, W. (2011). RETINOBLASTOMA-RELATED PROTEIN controls the transition to autotrophic plant development. Development 138, 2977-2986.

Han, S.K., Wu, M.F., Cui, S., and Wagner, D. (2015). Roles and activities of chromatin remodeling ATPases in plants. Plant J 83, 62-77.

Harada, J.J., and Pelletier, J. (2012). Genome-wide analyses of gene activity during seed development. Seed Science Research 22, S15-S22.

Hecker, A., Brand, L.H., Peter, S., Simoncello, N., Kilian, J., Harter, K., Gaudin, V., and Wanke, D. (2015). The Arabidopsis GAGA-Binding Factor BASIC PENTACYSTEINE6 Recruits the POLYCOMB-REPRESSIVE COMPLEX1 Component LIKE HETEROCHROMATIN PROTEIN1 to GAGA DNA Motifs. Plant Physiol 168, 1013-1024.

Henderson, J.T., Li, H.-C., Rider, S.D., Mordhorst, A.P., Romero-Severson, J., Cheng, J.-C., Robey, J., Sung, Z.R., de Vries, S.C., and Ogas, J. (2004). PICKLE Acts throughout the Plant to Repress Expression of Embryonic Traits and May Play a Role in Gibberellin-Dependent Responses. Plant Physiol. 134, 995-1005.

Ho, K.K., Zhang, H., Golden, B.L., and Ogas, J. (2013). PICKLE is a CHD subfamily II ATPdependent chromatin remodeling factor. Biochim Biophys Acta 1829, 199-210.

Horstman, A., Li, M., Heidmann, I., Weemen, M., Chen, B., Muino, J.M., Angenent, G.C., and Boutilier, K. (2017). The BABY BOOM Transcription Factor Activates the LEC1-ABI3-FUS3LEC2 Network to Induce Somatic Embryogenesis. Plant Physiol 175, 848-857.

Hou, X., Zhou, J., Liu, C., Liu, L., Shen, L., and Yu, H. (2014). Nuclear factor Y-mediated H3K27me3 demethylation of the SOC1 locus orchestrates flowering responses of Arabidopsis. Nature Communications 5, 4601. 
Huang, M., Hu, Y., Liu, X., Li, Y., and Hou, X. (2015a). Arabidopsis leafy cotyledon1 mediates postembryonic development via interacting with phytochrome-interacting factor4. Plant Cell 27, 30993111.

Huang, M., Hu, Y., Liu, X., Li, Y., and Hou, X. (2015b). Arabidopsis LEAFY COTYLEDON1 controls cell fate determination during post-embryonic development. Front Plant Sci 6, 955.

Ikeuchi, M., Iwase, A., Rymen, B., Harashima, H., Shibata, M., Ohnuma, M., Breuer, C., Morao, A.K., de Lucas, M., De Veylder, L., Goodrich, J., Brady, S.M., Roudier, F., and Sugimoto, K. (2015). PRC2 represses dedifferentiation of mature somatic cells in Arabidopsis. Nat Plants 1, 15089.

Iwase, A., Mita, K., Nonaka, S., Ikeuchi, M., Koizuka, C., Ohnuma, M., Ezura, H., Imamura, J., and Sugimoto, K. (2015). WIND1-based acquisition of regeneration competency in Arabidopsis and rapeseed. J Plant Res 128, 389-397.

Jia, H., McCarty, D.R., and Suzuki, M. (2013). Distinct roles of LAFL network genes in promoting the embryonic seedling fate in the absence of VAL repression. Plant Physiol. 163, 1293-1305.

Jia, H., Suzuki, M., and McCarty, D.R. (2014). Regulation of the seed to seedling developmental phase transition by the LAFL and VAL transcription factor networks. Interdiscip. Rev. Dev. Biol. 3, 135-145.

Jing, Y., Zhang, D., Wang, X., Tang, W., Wang, W., Huai, J., Xu, G., Chen, D., Li, Y., and Lin, R. (2013). Arabidopsis chromatin remodeling factor PICKLE interacts with transcription factor HY5 to regulate hypocotyl cell elongation. Plant Cell 25, 242-256.

Junker, A., and Baumlein, H. (2012). Multifunctionality of the LEC1 transcription factor during plant development. Plant Signal Behav 7, 1718-1720.

Junker, A., Monke, G., Rutten, T., Keilwagen, J., Seifert, M., Thi, T.M., Renou, J.P., Balzergue, S., Viehover, P., Hahnel, U., Ludwig-Muller, J., Altschmied, L., Conrad, U., Weisshaar, B., and Baumlein, H. (2012). Elongation-related functions of LEAFY COTYLEDON1 during the development of Arabidopsis thaliana. Plant J. 71, 427-442.

Kanno, Y., Jikumaru, Y., Hanada, A., Nambara, E., Abrams, S.R., Kamiya, Y., and Seo, M. (2010). Comprehensive hormone profiling in developing Arabidopsis seeds: examination of the site of ABA biosynthesis, ABA transport and hormone interactions. Plant Cell Physiol 51, 1988-2001.

Kawakatsu, T., Nery, J.R., Castanon, R., and Ecker, J.R. (2017). Dynamic DNA methylation reconfiguration during seed development and germination. Genome Biol 18, 171.

Kawashima, T., and Berger, F. (2014). Epigenetic reprogramming in plant sexual reproduction. Nat Rev Genet 15, 613-624.

Keith, K., Kraml, M., Dengler, N.G., and McCourt, P. (1994). fusca3: A Heterochronic Mutation Affecting Late Embryo Development in Arabidopsis. Plant Cell 6, 589-600.

Kelsey, G., Stegle, O., and Reik, W. (2017). Single-cell epigenomics: Recording the past and predicting the future. Science 358, 69-75.

Kim, D., Cho, Y.H., Ryu, H., Kim, Y., Kim, T.H., and Hwang, I. (2013). BLH1 and KNAT3 modulate ABA responses during germination and early seedling development in Arabidopsis. Plant J 75, 755-766.

Kim, S.Y., Lee, J., Eshed-Williams, L., Zilberman, D., and Sung, Z.R. (2012). EMF1 and PRC2 cooperate to repress key regulators of Arabidopsis development. PLoS Genet 8, e1002512.

Kuwabara, A., and Gruissem, W. (2014). Arabidopsis RETINOBLASTOMA-RELATED and Polycomb group proteins: cooperation during plant cell differentiation and development. J Exp Bot 65, 2667-2676.

Kwong, R.W., Bui, A.Q., Lee, H., Kwong, L.W., Fischer, R.L., Goldberg, R.B., and Harada, J.J. (2003). LEAFY COTYLEDON1-LIKE Defines a Class of Regulators Essential for Embryo Development. Plant Cell 15, 5-18.

Lara, P., Oñate-Sànchez, L., Abraham, Z., Ferrándiz, C., Díaz, I., Carbonero, P., and VicenteCarbajosa, J. (2003). Synergistic activation of seed storage protein gene expression in Arabidopsis by ABI3 and two bZIPs related to OPAQUE2. J. Biol. Chem., 21003-21011.

Lee, K., and Seo, P.J. (2018). Dynamic Epigenetic Changes during Plant Regeneration. Trends Plant Sci 23, 235-247. 
Lehti-Shiu, M.D., Panchy, N., Wang, P., Uygun, S., and Shiu, S.H. (2017). Diversity, expansion, and evolutionary novelty of plant DNA-binding transcription factor families. Biochim Biophys Acta 1860, 3-20.

Li, Y., Jin, K., Zhu, Z., and Yang, J. (2010). Stepwise origin and functional diversification of the AFL subfamily B3 genes during land plant evolution. J Bioinform Comput Biol 8 Suppl 1, 33-45.

Libault, M., Pingault, L., Zogli, P., and Schiefelbein, J. (2017). Plant Systems Biology at the SingleCell Level. Trends Plant Sci 22, 949-960.

Lin, J.Y., Le, B.H., Chen, M., Henry, K.F., Hur, J., Hsieh, T.F., Chen, P.Y., Pelletier, J.M., Pellegrini, M., Fischer, R.L., Harada, J.J., and Goldberg, R.B. (2017). Similarity between soybean and Arabidopsis seed methylomes and loss of non-CG methylation does not affect seed development. Proc Natl Acad Sci U S A 114, E9730-E9739.

Liu, J., Deng, S., Wang, H., Ye, J., Wu, H.W., Sun, H.X., and Chua, N.H. (2016). CURLY LEAF regulates gene sets coordinating seed size and lipid biosynthesis in arabidopsis. Plant Physiol. 171, 424-436.

Liu, P.P., Montgomery, T.A., Fahlgren, N., Kasschau, K.D., Nonogaki, H., and Carrington, J.C. (2007a). Repression of AUXIN RESPONSE FACTOR10 by microRNA160 is critical for seed germination and post-germination stages. Plant J 52, 133-146.

Liu, X., and Hou, X. (2018). Antagonistic Regulation of ABA and GA in Metabolism and Signaling Pathways. Front Plant Sci 9, 251.

Liu, Y., Koornneef, M., and Soppe, W.J. (2007b). The absence of histone H2B monoubiquitination in the Arabidopsis hub1 (rdo4) mutant reveals a role for chromatin remodeling in seed dormancy. Plant Cell 19, 433-444.

Lopez-Molina, L., Mongrand, B., McLachlin, D.T., Chait, B.T., and Chua, N.H. (2002). ABI5 acts downstream of $\mathrm{ABI} 3$ to execute an $\mathrm{ABA}$-dependent growth arrest during germination. Plant $\mathrm{J}$. 32, 317-328.

Lotan, T., Ohto, M., Yee, K.M., West, M.A., Lo, R., Kwong, R.W., Yamagishi, K., Fischer, R.L., Goldberg, R.B., and Harada, J.J. (1998). Arabidopsis LEAFY COTYLEDON1 is sufficient to induce embryo development in vegetative cells. Cell 93, 1195-1205.

Lu, Q.S., Paz, J.D., Pathmanathan, A., Chiu, R.S., Tsai, A.Y., and Gazzarrini, S. (2010). The Cterminal domain of FUSCA3 negatively regulates mRNA and protein levels, and mediates sensitivity to the hormones abscisic acid and gibberellic acid in Arabidopsis. Plant J 64, 100-113.

Luerssen, H., Kirik, V., Herrmann, P., and Misera, S. (1998). FUSCA3 encodes a protein with a conserved VP1/AB13-like B3 domain which is of functional importance for the regulation of seed maturation in Arabidopsis thaliana. Plant J 15, 755-764.

Magnani, E., Jimenez-Gomez, J.M., Soubigou-Taconnat, L., Lepiniec, L., and Fiume, E. (2017). Profiling the onset of somatic embryogenesis in Arabidopsis. BMC Genomics 18, 998.

Makarevich, G., Leroy, O., Akinci, U., Schubert, D., Clarenz, O., Goodrich, J., Grossniklaus, U., and Kohler, C. (2006). Different Polycomb group complexes regulate common target genes in Arabidopsis. EMBO Rep 7, 947-952.

Manan, S., Ahmad, M.Z., Zhang, G., Chen, B., Haq, B.U., Yang, J., and Zhao, J. (2017). Soybean LEC2 Regulates Subsets of Genes Involved in Controlling the Biosynthesis and Catabolism of Seed Storage Substances and Seed Development. Front Plant Sci 8, 1604.

Mayran, A., and Drouin, J. (2018). Pioneer transcription factors shape the epigenetic landscape. J Biol Chem.

McKibbin, R.S., Wilkinson, M.D., Bailey, P.C., Flintham, J.E., Andrew, L.M., Lazzeri, P.A., Gale, M.D., Lenton, J.R., and Holdsworth, M.J. (2002). Transcripts of Vp-1 homeologues are misspliced in modern wheat and ancestral species. Proc Natl Acad Sci U S A 99, 10203-10208.

Mehdi, S., Derkacheva, M., Ramstrom, M., Kralemann, L., Bergquist, J., and Hennig, L. (2016). The WD40 Domain Protein MSI1 Functions in a Histone Deacetylase Complex to Fine-Tune Abscisic Acid Signaling. Plant Cell 28, 42-54.

Meinke, D.W. (1992). A Homeotic Mutant of Arabidopsis-Thaliana with Leafy Cotyledons. Science 258, $1647-1650$.

Mendes, A., Kelly, A.A., van Erp, H., Shaw, E., Powers, S.J., Kurup, S., and Eastmond, P.J. (2013). bZIP67 regulates the omega-3 fatty acid content of Arabidopsis seed oil by activating fatty acid desaturase3. Plant Cell 25, 3104-3116. 
Merini, W., and Calonje, M. (2015). PRC1 is taking the lead in PcG repression. Plant J 83, 110-120.

Merini, W., Romero-Campero, F.J., Gomez-Zambrano, A., Zhou, Y., Turck, F., and Calonje, M. (2017). The Arabidopsis Polycomb Repressive Complex 1 (PRC1) Components AtBMI1A, B, and C Impact Gene Networks throughout All Stages of Plant Development. Plant Physiol 173, 627-641.

Molitor, A.M., Bu, Z., Yu, Y., and Shen, W.H. (2014). Arabidopsis AL PHD-PRC1 complexes promote seed germination through $\mathrm{H} 3 \mathrm{~K} 4 \mathrm{me} 3$-to-H3K27me3 chromatin state switch in repression of seed developmental genes. PLoS Genet 10, e1004091.

Monke, G., Seifert, M., Keilwagen, J., Mohr, M., Grosse, I., Hahnel, U., Junker, A., Weisshaar, B., Conrad, U., Baumlein, H., and Altschmied, L. (2012). Toward the identification and regulation of the Arabidopsis thaliana ABI3 regulon. Nucleic Acids Res 40, 8240-8254.

Mozgova, I., and Hennig, L. (2015). The polycomb group protein regulatory network. Annu Rev Plant Biol 66, 269-296.

Mozgova, I., Kohler, C., and Hennig, L. (2015). Keeping the gate closed: functions of the polycomb repressive complex PRC2 in development. Plant J 83, 121-132.

Mozgova, I., Munoz-Viana, R., and Hennig, L. (2017). PRC2 Represses Hormone-Induced Somatic Embryogenesis in Vegetative Tissue of Arabidopsis thaliana. PLoS Genet 13, e1006562.

Mu, J., Tan, H., Zheng, Q., Fu, F., Liang, Y., Zhang, J., Yang, X., Wang, T., Chong, K., Wang, X.J., and Zuo, J. (2008). LEAFY COTYLEDON1 is a key regulator of fatty acid biosynthesis in Arabidopsis. Plant Physiol. 148, 1042-1054.

Mu, Y., Zou, M., Sun, X., He, B., Xu, X., Liu, Y., Zhang, L., and Chi, W. (2017a). BASIC PENTACYSTEINE Proteins Repress ABSCISIC ACID INSENSITIVE4 Expression via Direct Recruitment of the Polycomb-Repressive Complex 2 in Arabidopsis Root Development. Plant Cell Physiol 58, 607-621.

Mu, Y., Liu, Y., Bai, L., Li, S., He, C., Yan, Y., Yu, X., and Li, Y. (2017b). Cucumber CsBPCs Regulate the Expression of CsABI3 during Seed Germination. Front Plant Sci 8, 459.

Muller, K., Bouyer, D., Schnittger, A., and Kermode, A.R. (2012). Evolutionarily conserved histone methylation dynamics during seed life-cycle transitions. PLoS One 7, e51532.

Narro-Diego, L., Lopez-Gonzalez, L., Jarillo, J.A., and Pineiro, M. (2017). The PHD-containing protein EARLY BOLTING IN SHORT DAYS regulates seed dormancy in Arabidopsis. Plant Cell Environ 40, 2393-2405.

Narsai, R., Gouil, Q., Secco, D., Srivastava, A., Karpievitch, Y.V., Liew, L.C., Lister, R., Lewsey, M.G., and Whelan, J. (2017). Extensive transcriptomic and epigenomic remodelling occurs during Arabidopsis thaliana germination. Genome Biol 18, 172.

Ng, D.W., Chandrasekharan, M.B., and Hall, T.C. (2004). The 5' UTR negatively regulates quantitative and spatial expression from the ABI3 promoter. Plant Mol. Biol. 54, 25-38.

Nodine, M.D., and Bartel, D.P. (2010). MicroRNAs prevent precocious gene expression and enable pattern formation during plant embryogenesis. Genes Dev. 24, 2678-2692.

Nonogaki, H. (2017). Seed Biology Updates - Highlights and New Discoveries in Seed Dormancy and Germination Research. Front Plant Sci 8, 524.

Nowak, K., and Gaj, M.D. (2016). Transcription Factors in the Regulation of Somatic Embryogenesis. In Somatic Embryogenesis: Fundamental Aspects and Applications, V.M. LoyolaVargas and N. Ochoa-Alejo, eds (Cham: Springer International Publishing), pp. 53-79.

Parcy, F., Valon, C., Kohara, A., Misera, S., and Giraudat, J. (1997). The ABSCISIC ACIDINSENSITIVE3, FUSCA3, and LEAFY COTYLEDON1 loci act in concert to control multiple aspects of Arabidopsis seed development. Plant Cell 9, 1265-1277.

Park, W., Li, J., Song, R., Messing, J., and Chen, X. (2002). CARPEL FACTORY, a Dicer homolog, and HEN1, a novel protein, act in microRNA metabolism in Arabidopsis thaliana. Curr Biol 12, 1484-1495.

Pelletier, J.M., Kwong, R.W., Park, S., Le, B.H., Baden, R., Cagliari, A., Hashimoto, M., Munoz, M.D., Fischer, R.L., Goldberg, R.B., and Harada, J.J. (2017). LEC1 sequentially regulates the transcription of genes involved in diverse developmental processes during seed development. Proc Natl Acad Sci U S A 114, E6710-E6719.

Peng, F.Y., and Weselake, R.J. (2013). Genome-wide identification and analysis of the B3 superfamily of transcription factors in Brassicaceae and major crop plants. Theor. Appl. Genet. 126, 1305-1319. 
Questa, J.I., Song, J., Geraldo, N., An, H., and Dean, C. (2016). Arabidopsis transcriptional repressor VAL1 triggers Polycomb silencing at FLC during vernalization. Science 353, 485-488.

Ramirez-Parra, E., and Gutierrez, C. (2007). The many faces of chromatin assembly factor 1 . Trends Plant Sci 12, 570-576.

Raz, V., Bergervoet, J.H., and Koornneef, M. (2001). Sequential steps for developmental arrest in Arabidopsis seeds. Development 128, 243-252.

Ringrose, L., and Paro, R. (2007). Polycomb/Trithorax response elements and epigenetic memory of cell identity. Development 134, 223-232.

Rodrigues, A.S., and Miguel, C.M. (2017). The pivotal role of small non-coding RNAs in the regulation of seed development. Plant Cell Rep 36, 653-667.

Roscoe, T.T., Guilleminot, J., Bessoule, J.J., Berger, F., and Devic, M. (2015). Complementation of Seed Maturation Phenotypes by Ectopic Expression of ABSCISIC ACID INSENSITIVE3, FUSCA3 and LEAFY COTYLEDON2 in Arabidopsis. Plant Cell Physiol 56, 1215-1228.

Ryu, H., Cho, H., Bae, W., and Hwang, I. (2014). Control of early seedling development by BES1/TPL/HDA19-mediated epigenetic regulation of ABI3. Nat Commun 5, 4138.

Sakai, K., Taconnat, L., Borrega, N., Yansouni, J., Brunaud, V., Paysant-Le Roux, C., Delannoy, E., Martin Magniette, M.L., Lepiniec, L., Faure, J.D., Balzergue, S., and Dubreucq, B. (2018). Combining laser-assisted microdissection (LAM) and RNA-seq allows to perform a comprehensive transcriptomic analysis of epidermal cells of Arabidopsis embryo. Plant Methods 14, 10.

Santos Mendoza, M., Dubreucq, B., Miquel, M., Caboche, M., and Lepiniec, L. (2005). LEAFY COTYLEDON 2 activation is sufficient to trigger the accumulation of oil and seed specific mRNAs in Arabidopsis leaves. FEBS Lett 579, 4666-4670.

Santos-Mendoza, M., Dubreucq, B., Baud, S., Parcy, F., Caboche, M., and Lepiniec, L. (2008). Deciphering gene regulatory networks that control seed development and maturation in Arabidopsis. Plant J 54, 608-620.

Schneider, A., Aghamirzaie, D., Elmarakeby, H., Poudel, A.N., Koo, A.J., Heath, L.S., Grene, R., and Collakova, E. (2016). Potential targets of VIVIPAROUS1/ABI3-LIKE1 (VAL1) repression in developing Arabidopsis thaliana embryos. Plant J. 85, 305-319.

Seefried, W.F., Willmann, M.R., Clausen, R.L., and Jenik, P.D. (2014). Global Regulation of Embryonic Patterning in Arabidopsis by MicroRNAs. Plant Physiol 165, 670-687.

Serivichyaswat, P., Ryu, H.S., Kim, W., Kim, S., Chung, K.S., Kim, J.J., and Ahn, J.H. (2015). Expression of the floral repressor miRNA156 is positively regulated by the AGAMOUS-like proteins AGL15 and AGL18. Mol Cells 38, 259-266.

Shen, Y., Devic, M., Lepiniec, L., and Zhou, D.X. (2015). Chromodomain, Helicase and DNAbinding CHD1 protein, CHR5, are involved in establishing active chromatin state of seed maturation genes. Plant Biotechnol J 13, 811-820.

Sijacic, P., Bajic, M., McKinney, E.C., Meagher, R.B., and Deal, R.B. (2018). Chromatin accessibility changes between Arabidopsis stem cells and mesophyll cells illuminate cell typespecific transcription factor networks. The Plant Journal in press, n/a-n/a.

Sreenivasulu, N., and Wobus, U. (2013). Seed-development programs: a systems biology-based comparison between dicots and monocots. Annu Rev Plant Biol 64, 189-217.

Srivastava, A.K., Lu, Y., Zinta, G., Lang, Z., and Zhu, J.-K. (2018). UTR-Dependent Control of Gene Expression in Plants. Trends in Plant Science 23, 248-259.

Stone, S.L., Kwong, L.W., Yee, K.M., Pelletier, J., Lepiniec, L., Fischer, R.L., Goldberg, R.B., and Harada, J.J. (2001). LEAFY COTYLEDON2 encodes a B3 domain transcription factor that induces embryo development. PNAS 98, 11806-11811.

Stone, S.L., Braybrook, S.A., Paula, S.L., Kwong, L.W., Meuser, J., Pelletier, J., Hsieh, T.F., Fischer, R.L., Goldberg, R.B., and Harada, J.J. (2008). Arabidopsis LEAFY COTYLEDON2 induces maturation traits and auxin activity: Implications for somatic embryogenesis. Proc Natl Acad Sci U S A 105, 3151-3156.

Sugliani, M., Brambilla, V., Clerkx, E.J., Koornneef, M., and Soppe, W.J. (2010). The conserved splicing factor SUA controls alternative splicing of the developmental regulator ABI3 in Arabidopsis. Plant Cell 22, 1936-1946. 
Sun, F., Liu, X., Wei, Q., Liu, J., Yang, T., Jia, L., Wang, Y., Yang, G., and He, G. (2017). Functional Characterization of TaFUSCA3, a B3-Superfamily Transcription Factor Gene in the Wheat. Front Plant Sci 8, 1133.

Suzuki, M., and McCarty, D.R. (2008). Functional symmetry of the B3 network controlling seed development. Curr Op Plant Biol 11, 548-553.

Suzuki, M., Wang, H.H.Y., and McCarty, D.R. (2007). Repression of the LEAFY COTYLEDON 1/B3 regulatory network in plant embryo development by VP1/ABSCISIC ACID INSENSITIVE 3-LIKE B3 genes. Plant Physiol. 143, 902-911.

Swain, S., Myers, Z.A., Siriwardana, C.L., and Holt, B.F., 3rd. (2017). The multifaceted roles of NUCLEAR FACTOR-Y in Arabidopsis thaliana development and stress responses. Biochim Biophys Acta 1860, 636-644.

Swaminathan, K., Peterson, K., and Jack, T. (2008). The plant B3 superfamily. Trends Plant Sci. 13, 647-655.

Tan, T., Sun, Y., Peng, X., Wu, G., Bao, F., He, Y., Zhou, H., and Lin, H. (2017). ABSCISIC ACID INSENSITIVE3 Is Involved in Cold Response and Freezing Tolerance Regulation in Physcomitrella patens. Front Plant Sci 8, 1599.

Tanaka, M., Kikuchi, A., and Kamada, H. (2008). The Arabidopsis histone deacetylases HDA6 and HDA19 contribute to the repression of embryonic properties after germination. Plant Physiol 146, 149-161.

Tang, L.P., Zhou, C., Wang, S.S., Yuan, J., Zhang, X.S., and Su, Y.H. (2017). FUSCA3 interacting with LEAFY COTYLEDON2 controls lateral root formation through regulating YUCCA4 gene expression in Arabidopsis thaliana. New Phytol 213, 1740-1754.

Tang, X., Lim, M.H., Pelletier, J., Tang, M., Nguyen, V., Keller, W.A., Tsang, E.W., Wang, A., Rothstein, S.J., Harada, J.J., and Cui, Y. (2012a). Synergistic repression of the embryonic programme by SET DOMAIN GROUP 8 and EMBRYONIC FLOWER 2 in Arabidopsis seedlings. J Exp Bot 63, 1391-1404.

Tang, X., Hou, A., Babu, M., Nguyen, V., Hurtado, L., Lu, Q., Reyes, J.C., Wang, A., Keller, W.A., Harada, J.J., Tsang, E.W., and Cui, Y. (2008). The Arabidopsis BRAHMA chromatinremodeling ATPase is involved in repression of seed maturation genes in leaves. Plant Physiol 147, $1143-1157$.

Tang, X., Bian, S., Tang, M., Lu, Q., Li, S., Liu, X., Tian, G., Nguyen, V., Tsang, E.W., Wang, A., Rothstein, S.J., Chen, X., and Cui, Y. (2012b). MicroRNA-mediated repression of the seed maturation program during vegetative development in Arabidopsis. PLoS Genet. 8, e1003091.

Tao, Z., Shen, L., Gu, X., Wang, Y., Yu, H., and He, Y. (2017). Embryonic epigenetic reprogramming by a pioneer transcription factor in plants. Nature 551, 124-128.

To, A., Valon, C., Savino, G., Guilleminot, J., Devic, M., Giraudat, J., and Parcy, F. (2006). A network of local and redundant gene regulation governs Arabidopsis seed maturation. Plant Cell 18, 1642-1651.

Trindade, I., Schubert, D., and Gaudin, V. (2017). Epigenetic Regulation of Phase Transitions in Arabidopsis thaliana. In Plant Epigenetics, N. Rajewsky, S. Jurga, and J. Barciszewski, eds (Cham: Springer International Publishing), pp. 359-383.

Troncoso-Ponce, M.A., Barthole, G., Tremblais, G., To, A., Miquel, M., Lepiniec, L., and Baud, S. (2016). Transcriptional Activation of Two Delta-9 Palmitoyl-ACP Desaturase Genes by MYB115 and MYB118 Is Critical for Biosynthesis of Omega-7 Monounsaturated Fatty Acids in the Endosperm of Arabidopsis Seeds. Plant Cell 28, 2666-2682.

Tsai, A.Y., and Gazzarrini, S. (2012). AKIN10 and FUSCA3 interact to control lateral organ development and phase transitions in Arabidopsis. Plant J 69, 809-821.

Tsuchiya, Y., Nambara, E., Naito, S., and McCourt, P. (2004). The FUS3 transcription factor functions through the epidermal regulator TTG1 during embryogenesis in Arabidopsis. Plant J. 37, 73-81.

Tsukagoshi, H., Morikami, A., and Nakamura, K. (2007). Two B3 domain transcriptional repressors prevent sugar-inducible expression of seed maturation genes in Arabidopsis seedlings. Proc. Natl. Acad. Sci. USA 104, 2543-2547. 
Tsukagoshi, H., Saijo, T., Shibata, D., Morikami, A., and Nakamura, K. (2005). Analysis of a Sugar Response Mutant of Arabidopsis Identified a Novel B3 Domain Protein That Functions as an Active Transcriptional Repressor. Plant Physiol. 138, 675-685.

Turck, F., Roudier, F., Farrona, S., Martin-Magniette, M.L., Guillaume, E., Buisine, N., Gagnot, S., Martienssen, R.A., Coupland, G., and Colot, V. (2007). Arabidopsis TFL2/LHP1 specifically associates with genes marked by trimethylation of histone H3 lysine 27. PLoS Genet 3, e86.

van Zanten, M., Zoll, C., Wang, Z., Philipp, C., Carles, A., Li, Y., Kornet, N.G., Liu, Y., and Soppe, W.J. (2014). HISTONE DEACETYLASE 9 represses seedling traits in Arabidopsis thaliana dry seeds. Plant J 80, 475-488.

Vashisht, D., and Nodine, M.D. (2014). MicroRNA functions in plant embryos. Biochem Soc Trans 42, 352-357.

Veerappan, V., Chen, N., Reichert, A.I., and Allen, R.D. (2014). HSI2/VAL1 PHD-like domain promotes $\mathrm{H} 3 \mathrm{~K} 27$ trimethylation to repress the expression of seed maturation genes and complex transgenes in Arabidopsis seedlings. BMC Plant Biol 14, 293.

Veerappan, V., Wang, J., Kang, M., Lee, J., Tang, Y., Jha, A.K., Shi, H., Palanivelu, R., and Allen, R.D. (2012). A novel HSI2 mutation in Arabidopsis affects the PHD-like domain and leads to derepression of seed-specific gene expression. Planta 236, 1-17.

Verdier, J., and Thompson, R.D. (2008). Transcriptional regulation of storage protein synthesis during dicotyledon seed filling. Plant Cell Physiol. 49, 1263-1271.

Vicente-Carbajosa, J., and Carbonero, P. (2005). Seed maturation: developing an intrusive phase to accomplish a quiescent state. Int J Dev Biol 49, 645-651.

Wang, F., and Perry, S.E. (2013). Identification of direct targets of FUSCA3, a key regulator of Arabidopsis seed development. Plant Physiol. 161, 1251-1264.

Wang, H., Caruso, L.V., Downie, A.B., and Perry, S.E. (2004). The Embryo MADS Domain Protein AGAMOUS-Like 15 Directly Regulates Expression of a Gene Encoding an Enzyme Involved in Gibberellin Metabolism. Plant Cell 16, 1206-1219.

Wang, H., Liu, C., Cheng, J., Liu, J., Zhang, L., He, C., Shen, W.H., Jin, H., Xu, L., and Zhang, Y. (2016). Arabidopsis Flower and Embryo Developmental Genes are Repressed in Seedlings by Different Combinations of Polycomb Group Proteins in Association with Distinct Sets of Cisregulatory Elements. PLoS Genet 12, e1005771.

Wang, X., Niu, Q.W., Teng, C., Li, C., Mu, J., Chua, N.H., and Zuo, J. (2009). Overexpression of PGA37/MYB118 and MYB115 promotes vegetative-to-embryonic transition in Arabidopsis. Cell Res 19, 224-235.

Wang, Y., Deng, D., Zhang, R., Wang, S., Bian, Y., and Yin, Z. (2012). Systematic analysis of plant-specific B3 domain-containing proteins based on the genome resources of 11 sequenced species. Mol. Biol. Rep. 39, 6267-6282.

Wang, Y., Zhang, T., Song, X., Zhang, J., Dang, Z., Pei, X., and Long, Y. (2018). Identification and functional analysis of two alternatively spliced transcripts of ABSCISIC ACID INSENSITIVE3 (ABI3) in linseed flax (Linum usitatissimum L.). PLoS One 13, e0191910.

Willmann, M.R., Mehalick, A.J., Packer, R.L., and Jenik, P.D. (2011). MicroRNAs regulate the timing of embryo maturation in Arabidopsis. Plant Physiol 155, 1871-1884.

Wójcik, A.M., Nodine, M.D., and Gaj, M.D. (2017). miR160 and miR166/165 Contribute to the LEC2-Mediated Auxin Response Involved in the Somatic Embryogenesis Induction in Arabidopsis. Frontiers in Plant Science 8.

Wojcikowska, B., Jaskola, K., Gasiorek, P., Meus, M., Nowak, K., and Gaj, M.D. (2013). LEAFY COTYLEDON2 (LEC2) promotes embryogenic induction in somatic tissues of Arabidopsis, via YUCCA-mediated auxin biosynthesis. Planta 238, 425-440.

Wójcikowska, B., and Gaj, M. (2015). LEAFY COTYLEDON2-mediated control of the endogenous hormone content: implications for the induction of somatic embryogenesis in Arabidopsis. Plant Cell, Tissue and Organ Culture (PCTOC) 121, 255-258.

Xiao, J., and Wagner, D. (2015). Polycomb repression in the regulation of growth and development in Arabidopsis. Curr Opin Plant Biol 23, 15-24.

Xiao, J., Jin, R., Yu, X., Shen, M., Wagner, J.D., Pai, A., Song, C., Zhuang, M., Klasfeld, S., He, C., Santos, A.M., Helliwell, C., Pruneda-Paz, J.L., Kay, S.A., Lin, X., Cui, S., Garcia, M.F., Clarenz, O., Goodrich, J., Zhang, X., Austin, R.S., Bonasio, R., and Wagner, D. (2017). Cis 
and trans determinants of epigenetic silencing by Polycomb repressive complex 2 in Arabidopsis. Nat Genet 49, 1546-1552.

Xu, F., Kuo, T., Rosli, Y., Liu, M.S., Wu, L., Oliver Chen, L.F., Fletcher, J.C., Sung, Z.R., and Pu, L. (2018). Trithorax group proteins act together with a Polycomb group protein to maintain chromatin integrity for epigenetic silencing during seed germination in Arabidopsis. Mol Plant.

Xu, Y., Guo, C., Zhou, B., Li, C., Wang, H., Zheng, B., Ding, H., Zhu, Z., Peragine, A., Cui, Y., Poethig, S., and Wu, G. (2016). Regulation of Vegetative Phase Change by SWI2/SNF2 Chromatin Remodeling ATPase BRAHMA. Plant Physiol 172, 2416-2428.

Yamamoto, A., Kagaya, Y., Toyoshima, R., Kagaya, M., Takeda, S., and Hattori, T. (2009). Arabidopsis NF-YB subunits LEC1 and LEC1-LIKE activate transcription by interacting with seedspecific ABRE-binding factors. Plant $\mathrm{J}$.

Yamamoto, A., Kagaya, Y., Usui, H., Hobo, T., Takeda, S., and Hattori, T. (2010). Diverse roles and mechanisms of gene regulation by the Arabidopsis seed maturation master regulator FUS3 revealed by microarray analysis. Plant Cell Physiol 51, 2031-2046.

Yamamoto, A., Yoshii, M., Murase, S., Fujita, M., Kurata, N., Hobo, T., Kagaya, Y., Takeda, S., and Hattori, T. (2014). Cell-by-cell developmental transition from embryo to post-germination phase revealed by heterochronic gene expression and ER-body formation in Arabidopsis leafy cotyledon mutants. Plant Cell Physiol. 55, 2112-2125.

Yang, C., Bratzel, F., Hohmann, N., Koch, M., Turck, F., and Calonje, M. (2013). VAL- and AtBMI1-mediated H2Aub initiate the switch from embryonic to postgerminative growth in Arabidopsis. Curr Biol 23, 1324-1329.

Yang, R., Zheng, Z., Chen, Q., Yang, L., Huang, H., Miki, D., Wu, W., Zeng, L., Liu, J., Zhou, J.X., Ogas, J., Zhu, J.K., He, X.J., and Zhang, H. (2017a). The developmental regulator PKL is required to maintain correct DNA methylation patterns at RNA-directed DNA methylation loci. Genome Biol 18, 103.

Yang, W., Zhang, W., and Wang, X. (2017b). Post-translational control of ABA signalling: the roles of protein phosphorylation and ubiquitination. Plant Biotechnol J 15, 4-14.

Yoshii, M., Yamamoto, A., Kagaya, Y., Takeda, S., and Hattori, T. (2015). The Arabidopsis transcription factor NAI1 is required for enhancing the active histone mark but not for removing the repressive mark on PYK10, a seedling-specific gene upon embryonic-to-postgerminative developmental phase transition. Plant Signal Behav 10, e1105418.

Yuan, W., Luo, X., Li, Z., Yang, W., Wang, Y., Liu, R., Du, J., and He, Y. (2016). A cis cold memory element and a trans epigenome reader mediate Polycomb silencing of FLC by vernalization in Arabidopsis. Nat Genet 48, 1527-1534.

Zaret, K.S. (2018). Pioneering the chromatin landscape. Nat Genet 50, 167-169.

Zhang, D., Jing, Y., Jiang, Z., and Lin, R. (2014a). The Chromatin-Remodeling Factor PICKLE Integrates Brassinosteroid and Gibberellin Signaling during Skotomorphogenic Growth in Arabidopsis. Plant Cell 26, 2472-2485.

Zhang, H., Bishop, B., Ringenberg, W., Muir, W.M., and Ogas, J. (2012). The CHD3 remodeler PICKLE associates with genes enriched for trimethylation of histone H3 lysine 27. Plant Physiol. 159, 418-432.

Zhang, H., Rider, S.D., Jr., Henderson, J.T., Fountain, M., Chuang, K., Kandachar, V., Simons, A., Edenberg, H.J., Romero-Severson, J., Muir, W.M., and Ogas, J. (2008). The CHD3 remodeler PICKLE promotes trimethylation of histone H3 lysine 27. J Biol Chem 283, 2263722648

Zhang, X., Garreton, V., and Chua, N.-H. (2005). The AIP2 E3 ligase acts as a novel negative regulator of $\mathrm{ABA}$ signaling by promoting $\mathrm{ABI} 3$ degradation

10.1101/gad.1318705. Genes Dev. 19, 1532-1543.

Zhang, X., Germann, S., Blus, B.J., Khorasanizadeh, S., Gaudin, V., and Jacobsen, S.E. (2007). The Arabidopsis LHP1 protein colocalizes with histone H3 Lys27 trimethylation. Nat Struct Mol Biol 14, 869-871.

Zhang, Y., Cao, G., Qu, L.J., and Gu, H. (2009). Involvement of an R2R3-MYB transcription factor gene AtMYB118 in embryogenesis in Arabidopsis. Plant Cell Rep 28, 337-346. 
Zhang, Y., Clemens, A., Maximova, S.N., and Guiltinan, M.J. (2014b). The Theobroma cacao B3 domain transcription factor TcLEC2 plays a duel role in control of embryo development and maturation. BMC Plant Biol 14, 106.

Zhao, H., Wu, D., Kong, F., Lin, K., Zhang, H., and Li, G. (2016). The Arabidopsis thaliana Nuclear Factor Y Transcription Factors. Frontiers in Plant Science 7, 2045.

Zhao, M., Yang, S., Liu, X., and Wu, K. (2015). Arabidopsis histone demethylases LDL1 and LDL2 control primary seed dormancy by regulating DELAY OF GERMINATION 1 and ABA signalingrelated genes. Front Plant Sci 6, 159.

Zheng, J., Chen, F., Wang, Z., Cao, H., Li, X., Deng, X., Soppe, W.J., Li, Y., and Liu, Y. (2012). A novel role for histone methyltransferase KYP/SUVH4 in the control of Arabidopsis primary seed dormancy. New Phytol 193, 605-616.

Zheng, Y., Ren, N., Wang, H., Stromberg, A.J., and Perry, S.E. (2009). Global identification of targets of the Arabidopsis MADS domain protein AGAMOUS-Like15. Plant Cell 21, 2563-2577.

Zhiguo, E., Li, T., Zhang, H., Liu, Z., Deng, H., Sharma, S., Wei, X., Wang, L., Niu, B., and Chen, C. (2018). A group of Nuclear Factor Y Transcription Factors are Sub-Functionalized During Endosperm Development in Monocots. J Exp Bot 69, 2495-2510.

Zhou, Y., Romero-Campero, F.J., Gomez-Zambrano, A., Turck, F., and Calonje, M. (2017). H2A monoubiquitination in Arabidopsis thaliana is generally independent of LHP1 and PRC2 activity. Genome Biol 18, 69.

Zhou, Y., Tan, B., Luo, M., Li, Y., Liu, C., Chen, C., Yu, C.W., Yang, S., Dong, S., Ruan, J., Yuan, L., Zhang, Z., Zhao, L., Li, C., Chen, H., Cui, Y., Wu, K., and Huang, S. (2013). HISTONE DEACETYLASE19 interacts with HSL1 and participates in the repression of seed maturation genes in Arabidopsis seedlings. Plant Cell 25, 134-148.

Zhu, C., and Perry, S.E. (2005). Control of expression and autoregulation of AGL15, a member of the MADS-box family. Plant J. 41, 583-594.

Zhu, Y., Xie, Z., Wang, J., Liu, Y., and Wang, J. (2013). Cloning and characterization of two genes coding for the histone acetyltransferases, Elp3 and Mof, in brown planthopper (BPH), Nilaparvata lugens (Stal). Gene 513, 63-70. 


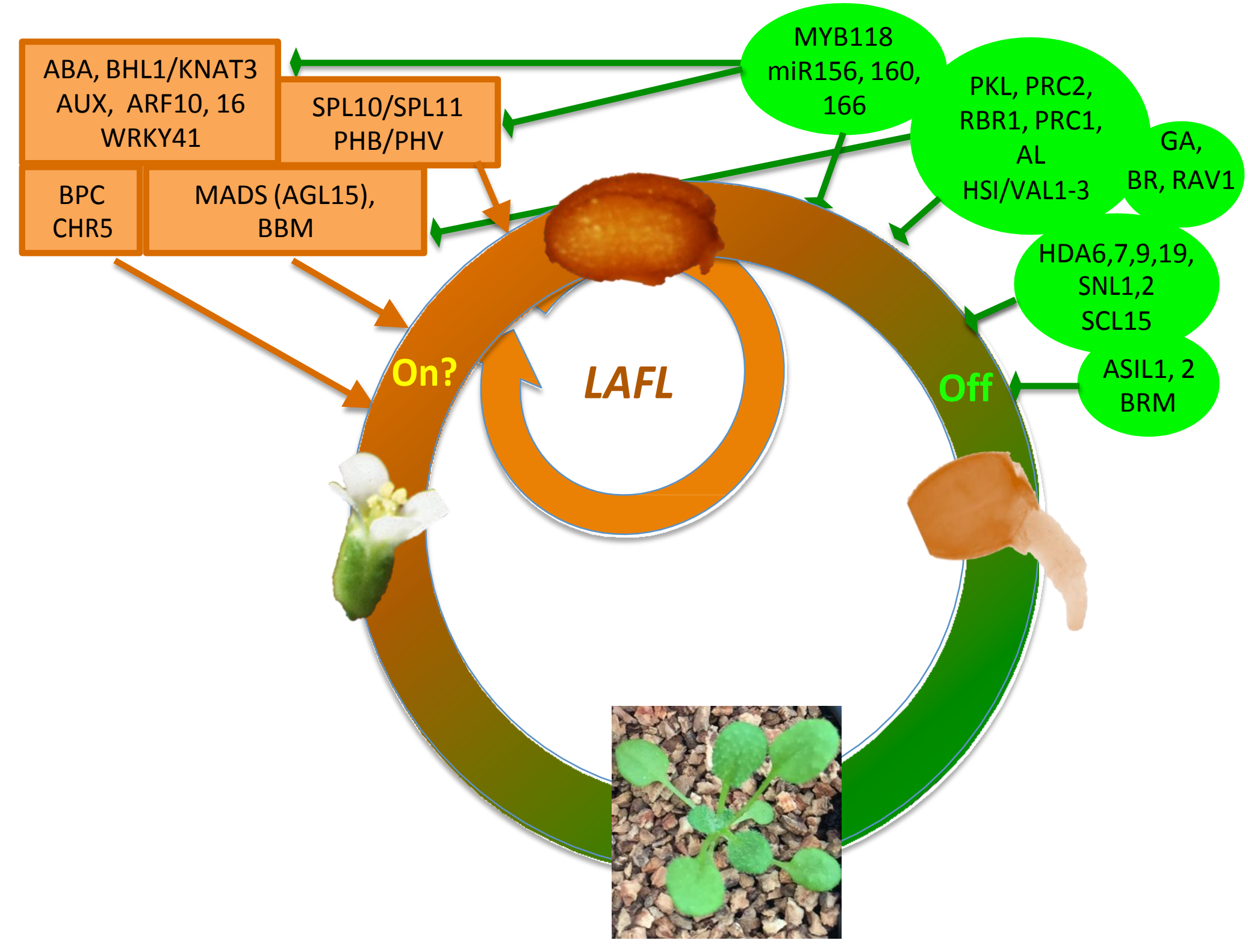



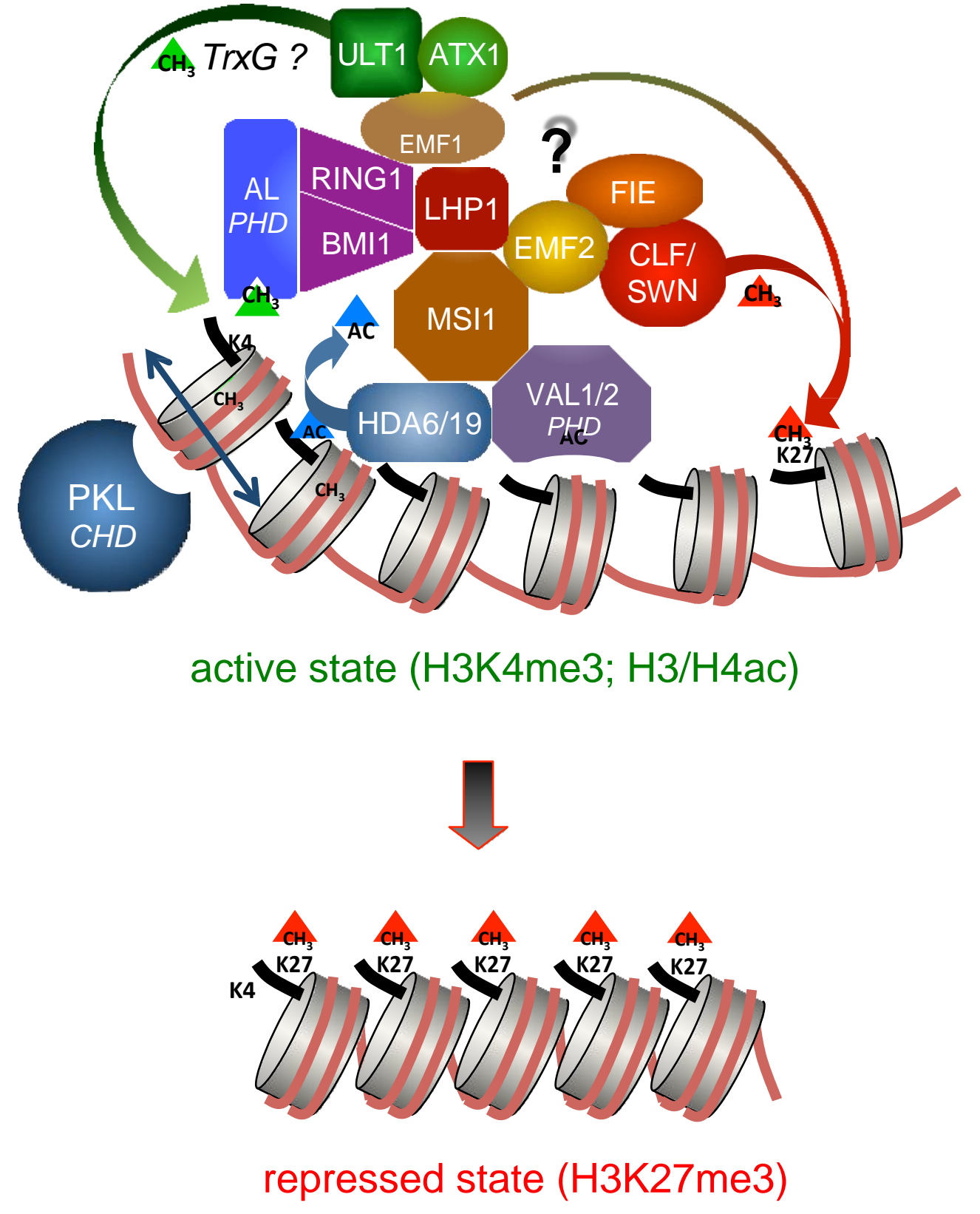